\title{
PRESIDENTIAL INFLUENCE AND COMPETITIVE GRANT FUNDING:
}

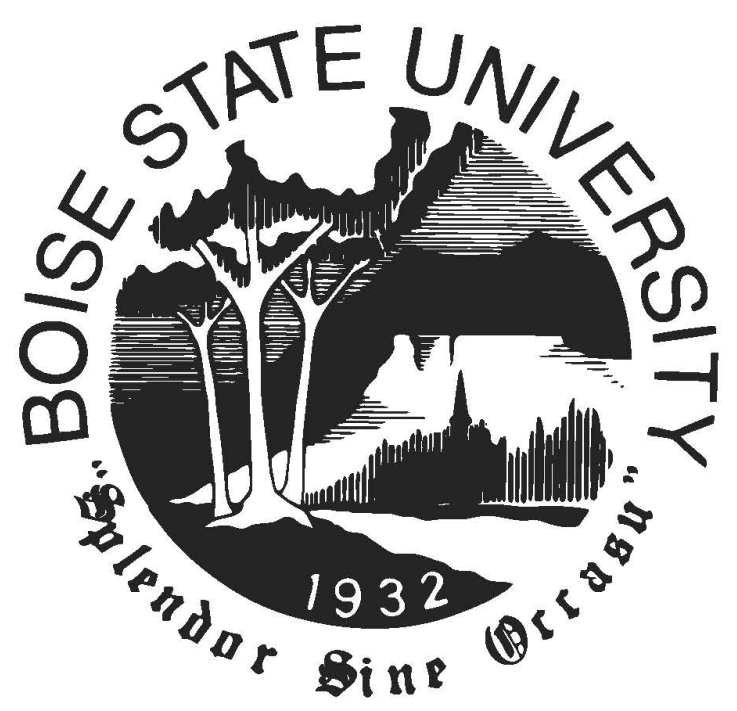

A thesis

submitted in partial fulfillment

of the requirements for the degree of

Masters of Science in Economics

Boise State University 
Benjamin Albert

SOME RIGHTS RESERVED

(c)

This work is licensed under a Creative

Commons Attribution-Noncommercial

4.0 International License. 


\section{BOISE STATE UNIVERSITY GRADUATE COLLEGE \\ DEFENSE COMMITTEE AND FINAL READING APPROVALS}

of the thesis submitted by

Benjamin Albert

Thesis Title: $\quad$ Presidential Influence and Competitive Grant Funding: Reexamining Presidential Pork

Date of Final Oral Examination: 08 March 2020

The following individuals read and discussed the thesis submitted by student Benjamin Albert, and they evaluated the student's presentation and response to questions during the final oral examination. They found that the student passed the final oral examination.

Kelly Chen, Ph.D. Chair, Supervisory Committee

Christine Loucks, Ph.D. Co-Chair, Supervisory Committee

Michail Fragkias, Ph.D. Member, Supervisory Committee

The final reading approval of the thesis was granted by Kelly Chen, Ph.D., Chair of the Supervisory Committee. The thesis was approved by the Graduate College. 


\section{Abstract}

How does partisan alignment with the president affect the distribution of federal competitive grant funding? This analysis contributes to the literature on distributive politics by reexamining the relationship between alignment with the president and competitive grant funding over the time period of 2001 to 2017. Furthermore, the analysis will test if the relationship between alignment and competitive grant funding changed after the enactment of the 2011 earmark moratorium. Fractional probit regression is used to model the relationship between a representative's partisan alignment with the president and the portion of annual competitive grant funding that their district receives. The results suggest that there is no relationship between alignment and competitive grant funding when looking at grant funding across all federal agencies. However, when only examining agencies that are susceptible to presidential influence a weak relationship emerges. Findings also suggest that this relationship developed after the enactment of the earmark moratorium. 


\section{Table of Contents}

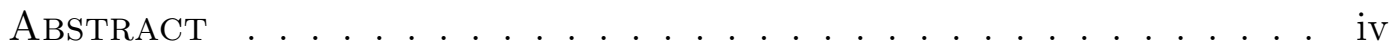

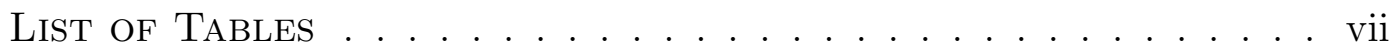

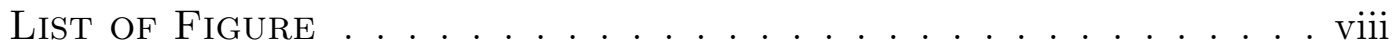

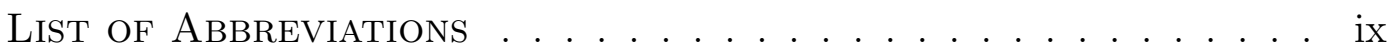

1 Introduction 1

2 Literature Review $\quad 4$

2.1 Distributive Politics . . . . . . . . . . . . . . . . . 4

2.2 Political Parties . . . . . . . . . . . . . . . . . . . . 7

2.3 The Executive Branch . . . . . . . . . . . . . . . . 8

$\begin{array}{llr}3 & \text { Background } & 11\end{array}$

3.1 The Budget Appropriations Process . . . . . . . . . . . . . . 12

3.2 Presidential Influence . . . . . . . . . . . . . . . . . . . 15

4 Data Description $\quad 17$

4.1 Political Control Variables . . . . . . . . . . . . . . . . . . 19

4.2 Socioeconomic Control Variables . . . . . . . . . . . . . . . . . 21

4.3 Descriptive Statistics . . . . . . . . . . . . . . . . 22

5 Methodology 33

$\begin{array}{lll}6 & \text { Results } & 37\end{array}$

6.1 Earmark Era . . . . . . . . . . . . . . . . . . 47 
6.2 Post Earmark Era . . . . . . . . . . . . . . . . . . . . . 53

6.3 Event Study . . . . . . . . . . . . . . . . . . . . . . . . . . 58

$\begin{array}{lll}7 & \text { Conclusion } & 61\end{array}$

$\begin{array}{ll}\text { References } & 64\end{array}$

$\begin{array}{ll}\text { Appendices } & 73\end{array}$ 


\section{List of Tables}

4.1 Implicitly Missing Congressional Districts . . . . . . . . . . . 18

4.2 Average Funding Per Year . . . . . . . . . . . . . . . . . 30

4.3 Difference of Mean Test . . . . . . . . . . . . . . . . . . . . . 32

6.1 Alignment and Competitive Grant Funding . . . . . . . . . . 39

6.2 Individual Agencies Sign Chart . . . . . . . . . . . . . . . . 41

6.3 Alignment and Filtered Competitive Grant Funding . . . . 42

6.4 Election Years . . . . . . . . . . . . . . . . . 44

6.5 Interaction Between State and District Alignment . . . . . . 46

6.6 Earmark Era . . . . . . . . . . . . . . . . . . . . . . . 49

6.7 Earmark Era: Elections . . . . . . . . . . . . . . . 50

6.8 Earmark Era: Interaction between State and District Alignment . . . . . . . . . . . . . . . . 52

6.9 Post Earmark Era . . . . . . . . . . . . . . . . . . . . 54

6.10 Post Earmark Era: Elections . . . . . . . . . . . . . . . 55

6.11 Post Earmark Era: Interaction between State and District Alignment . . . . . . . . . . . . . . . . . 57 


\section{List of Figures}

3.1 Budget Approval Process . . . . . . . . . . . . . . . . 13

4.1 Portion Of Total Grant Funding by Partisanship . . . . . . . 20

4.2 Geographic Distribution of Funds and Alignment: 2002-2017 29

4.3 Distribution of Portion of Grant Funding in Aligned and Dis-aligned Districts f . . . . . . . . . . . . . 31

6.1 Alignment Coefficient Plot . . . . . . . . . . . . 58

6.2 Interaction Between District and State Alignment . . . . . . 59 


\section{List of Abbreviations}

B.E.A. Bureau of Economic Analysis

B.U.I.L.D. Better Utilizing Investments to Leverage Development

C.N.C.S. Corporation for National Communication Service

D.O.C. Department Of Commerce

D.O.S. Department Of State

D.R.A. Delta Regional Authority

H.A.C. House of Representatives Appropriations Committee

H.O.R. House Of Representatives

H.U.D. Department of Housing and Urban Development

N.S.F. National Science Foundation

S.A.C. Senate Appropriations Committee

T.I.G.E.R. Transportation Investment Generating Economic Recovery

U.S. United States of America 


\section{Chapter 1}

\section{Introduction}

How does partisan alignment with the president affect the geographic distribution of federal competitive grant funding? A wide range of research in the field of public choice examines the political factors that influence the distribution of federal funds. However, the majority of this research has focused on the U.S. Congress (Bertelli and Grose, 2009; Berry et al., 2010; Hudak, 2014). Distributive politics literature tends to focus on the role played by individual members of congress and committees in the grant funding allocation process (Collie, 1988; Shepsle and Weingast, 1981; Weingast, 1994; Clemens et al., 2015a), while strong party and party cartel models emphasize political parties within the congressional budget appropriations process (Levitt and Snyder, 1995; Cox and McCubbins, 2005). Far less attention has been focused on presidential influence on the grant allocation.

However, in recent years a new line of research has started to examine the president's role in the budget appropriations process. This strand of research finds that the president has a major effect on the distribution of federal funds. There is growing evidence that the president influences the flow of federal dollars to target swing voters, his core supporters, and informed voters (Stromberg, 2004; Yong and Sobel, 2013; Larcinese et al, 2012). One seminal work in this field is from Berry et al. (2010), which found that Congressional districts represented by members of the same political party as the president received higher levels of federal spending over the time period of 1984 to 2007. This paper will reexamine 
this relationship with competitive grant funds over the time period 2001-2017.

The analysis will adopt the same identification strategy as Berry et al. (2010). The model identification arises from the fact that a change in district alignment can be the result of two different independent factors. First, alignment can change as a result of a change in the political party of the representative holding the partisanship of the president constant. Second, alignment may change as a result of a change in the partisanship of the president holding the partisanship of the representative constant. Congressional district and year fixed effects are also included in the model along with economic and political control variables.

This study extends Berry et al. (2010) research in three major ways. First, the dependent variable is the portion of annual competitive grant funding that a district receives in a given year. Therefore, a fractional probit regression model will be used to properly specify the functional form. Second, the importance of alignment between the president and at least one of the state's senators will also be tested, and senate control variables will be added to the model. Third, the analysis will test if the relationship between partisan alignment with the president and competitive grant funding changed after the enactment of the earmark moratorium.

In 2011, the House of Representatives (H.O.R.) and the Senate both enacted a moratorium on earmarks. The moratorium was supposed to curtail corrupt behavior in earmarking and to decrease government spending. However, the effect of the earmark moratorium may have been to transfer the power and practice of earmarking from the congressional branch to the executive branch giving the president and his cabinet secretaries more influence in the grant appropriations process (White, 2015). Thus the topic of executive influence in distributive politics may be more relevant now due to the major changes in how federal grant funds are awarded that have occurred in the last decade.

My results suggest that partisan alignment with the president does not have an effect on total competitive grant funding. The state and congressional district 
alignment variables are not statically significant in any model that uses total grant fund as the dependent variable. However, this finding arises from heterogeneity in federal agencies. When grant funding from agencies that are susceptible to presidential influence is examined, there is evidence of a weak relationship between alignment and competitive grant funding. Furthermore, the relationship between competitive grant funding and alignment appears to have changed after the enactment of the earmark moratorium. During the period when earmarking was allowed, there is not a significant relationship between alignment and competitive grant funding. However, after the enactment of the moratorium the results suggest that aligned districts located in aligned states receive a larger share of annual competitive grant funding.

The paper is outlined as follows: Chapter 2 will review the literature on distributive politics. Chapter 3 describes the budget appropriations process and the channels for presidential influence. Chapter 4 contains a description of the data set. In Chapter 5 the research design and identification strategy is discussed. The results from the base model and the analysis examining if a structural break occurred in 2011 are discussed in Chapter 6. Finally, in Chapter 7 the paper concludes with a brief summary of the findings and suggests topics for future research. 


\section{Chapter 2}

\section{Literature Review}

There has been a large amount of research examining the political determinants of grant funding. This research can be broken up into three broad categories based on the different variables that are examined and theoretical frameworks that were proposed. The three primary categories are: distributive politics, political parties, and the executive branch.

\subsection{Distributive Politics}

Theories in distributive politics explain government spending as the result of a bargaining process where benefits, in the form of funds, are geographically distributed across districts. Weingast (1994) notes that a program can be considered a distributive program if it meets three criteria: divisibility, omnibus, and expenditure. A program is divisible if it is composed of a wide array of local projects that can be independently varied in size and funding amount. A program is considered omnibus if it is a conglomeration of many independent smaller projects. Lastly, the policy can be classified as an expenditure policy if its primary purpose is to allocate government funds.

One central aspect of early distributive politics theories was the universalism hypothesis first introduced by Mayhew (1974) and formalized by Weingast's (1979). The universalism hypothesis maintains that every member of Congress 
should receive some distributive funding because politicians are rational and seek to maximize the probability that they are reelected. Since distributive benefits take up a relatively small portion of the federal budget they typically occupy a low level of salience. Thus, the political costs of engaging in distributive politics are minimal. However, distributive programs provide highly concentrated benefits to the politician's home district or state. Thus, the political benefits of engaging in distributive politics are high. Therefore, members of Congress will over provide distributive programs and every member of Congress will seek to engage in distributive politics due to the low level of political costs (Collie 1988; Shepsle and Weingast 1981).

Despite widespread theoretical attention empirical evidence for the universalism hypothesis is fairly weak. Casico and Washington (2014) find some evidence of universalism at the state level. They examine the change in education spending allocated to predominantly African American localities after the removal of literacy test requirements for voter registration. The results indicate that the removal of the test led to a statistically significant increase in education spending in African American communities. However, this finding may be partially the result of the nature of the program. Education spending is highly visible to the local community and the benefits are concentrated to the local area. Stein and Bickers (1994b) find no support for universalism in the distribution of congressional outlays. Their finding suggests that two aspects of distributive politics theories must be reconsidered. First, that the public may not be aware of the benefits. Second, not all members of Congress have an equal ability to influence the flow of grant funds.

Lee (2003) argues that members of the HOR gain very little political benefits from grants allocated to their state because these funds may not reach their home district. Furthermore, members of the HOR cannot claim credit for funds that were allocated to their state and not their district. Lee finds that political factors have a much larger effect on the allocation of earmark funds than on grant-in-aid 
funds. This is due to the fact that House members can claim credit for earmarks but not grant in aid funds, which are distributed to states.

Members of Congress may also differ in their ability to extract distributive benefits. This is a core aspect of modern distributive politics research that was overlooked by the early theorists (Stein and Bickers, 1994b). Research has found mixed support for a positive relationship between seniority and distributive spending. Lazarus (2010) finds that more senior members received more funds in the 2008 fiscal year, while Fowler and Hill (2015) find no evidence of this relationship. There is also mixed support for vulnerable incumbents receiving more distributive funds. Some research finds support for this theory (Stein and Bickers 1994a; Lazarus 2010), while other studies find no evidence of a relationship between electoral vulnerability and distributive spending (Clemens, et al., 2015b; Balla et al., 2002).

There is a large body of evidence suggesting that committees play a major role in distributive politics. Research finds that committee members tend to receive more distributive benefits from policies in the areas which their committee has oversight (Knight, 2005; Clemens et al., 2015b). A large amount of research also finds that members of the appropriations committee receive more distributive funding (Lazarus, 2010; Lazarus 2009, De Figueiredo and Silverman, 2006, Clemens et al., 2015b). There have also been mixed findings concerning if a member's position within the committee affects the amount of distributive benefits they receive. Clemens et al (2015b) find that appropriations committee chairs, cardinals, and members of the house leadership all received more earmark receipts in the 2008 fiscal year, while Kasdin and Lin (2015) and Lazarus (2010) found no evidence of a relationship between committee position and distributive benefits. 


\section{$2.2 \quad$ Political Parties}

Early research in distributive politics largely overlooked the role of political parties. This was due to the predominant view that political parties were weak institutions in American politics. That thought dominated much of the 20th century research (Downs, 1957; Levitt and Snyder, 1995). However, the growth in the ideological divergence between the Republican and Democratic political parties since 1980 has led to an increase in research examining the relationship between political parties and distributive politics.

Early models that emphasize the role of political parties in distributive politics typically assume that political parties are rational unitary actors. Parties maximize re-election and policy goals through the use of government funds and are typically constrained by the need to have a balanced budget. It is typically assumed that parties operate under some level of uncertainty about the distribution of partisan support in the electorate (Dixit and Londregan, 1996). Levitt and Snyder (1995) state that these models typically predict that the majority party allocates government funds between policy goals and member districts in a way that is optimal for their legislative interests, with a high level of precision.

This work culminated with Cox and McCubbins' (1986) seminal party cartel theory, which explains how the majority party can monopolize the legislative agenda. In this model, the majority party attempts to monopolize the legislative agenda by placing its members on committees and in leadership positions that have major influence over which bills will be voted on. A party cartel is achieved if members of the majority party hold most of the seats in Congress with agendasetting power. Then members of the majority party can block bills from coming to the floor that conflict with the majority party's interests. If the majority party can secure a cartel over the legislative agenda they will also divert more resources to party members. Thus, benefits should be distributed disproportionately towards members of the majority party. However, the majority party will still allow some 
resources to flow to the minority party because they would like to share part of blame for pork barrel politics with the minority party (Balla et al., 2002).

There has been a large amount of empirical research examining the role of the majority party in distributive politics. The majority of this research finds that members of the majority party receive disproportionately more federal funds while minority party members still receiving some federal spending (Balla et al., 2002; Albouy, 2013; Lazarus and Steigerwalt, 2009). Research also finds that states with a large majority party vote share receive more funds (Levitt and Snyder, 1995), and electorally vulnerable majority party members receive more funding (Lazarus, 2009). Lastly, Grossman (1994) finds that aligned state legislatures received more grant funding.

\subsection{The Executive Branch}

Although the majority of academic research focuses on Congress there is some theoretical and empirical evidence of presidential influence in the grant allocation process. Berry et al. (2010) note that there are two channels with which the president can influence the appropriations process; ex-ante and ex-post influence. The ex-ante channel concerns the influence that is at the president's disposal before a federal budget has been passed. This primarily takes the form of proposal power and veto power. Ex-post influence occurs after the federal budget has been passed. The president can influence which projects get funding by appointing cabinet secretaries that will fund projects which conform to the president's interests. Research finds that the President directs more distributive benefits towards swing voters in competitive states during years in which the president is running for re-election (Stromberg, 2004; and Kang, 2018), and also redirects funds to his core constituency in order to pay them back for their support (Young and Sobel, 2013; Larcinese et al., 2006).

There is also evidence that executive agencies face more than just ex-post 
pressure from the President. Ting (2012) notes that agencies are also under congressional pressure. In Ting's model, the distribution of federal grants is the result of Congress's decision to professionalize or politicize the budget. Under a professionalized budgetary regime the funds are allocated according to the quality of the proposed projects. In a politicized regime, the distribution of funds are allocated according to political power. Ting's results indicate that legislatures will politicize the budgeting process if there is a high probability of the politicized budget being accepted.

Kasdin and Lin (2015) extend this model to incorporate the interest of bureaucratic agencies. Agencies maximize their policy goals subject to the need to secure funding. Securing funding is a function of congressional support. Kasdin and Lin note that there are three possible equilibrium conditions. First, the majority party supports the agency. If the agency has the support of the majority party, then the agency will not alter how it distributes funding. Second, the majority party is indifferent towards the agency. Under this regime, the agency will not alter how it distributes funds. Lastly, the majority party is opposed to the agency. If the majority party is opposed to the agency, then the agency will allocate more funds to districts of majority party members in order to buy their support.

There is some empirical evidence of congressional ex-post budgetary influence. Mills et al. (2016) find that the moratorium on earmarks reduced the level of influence that Congress has over the distribution of federal funds. However, their results indicate that members of Congress can still circumvent the ban through informal means of communication with the bureaucracy. Kasdin and Lin (2015) examine the change in the distribution of agency funding after the 2006 election when the majority party shifted from the Republican Party to the Democratic Party. Their results indicate that agencies that are supported by Democrats or agencies which Democrats are indifferent towards did not have a statistically significant change in their spending patterns. However, agencies favored by Republicans had a statistically significant shift in spending patterns toward Democratic-controlled 
districts 


\section{Chapter 3}

\section{Background}

As previously stated this paper will examine how partisan alignment between a congressional district's (state) representative (senator) and the president affects the portion of annual grant funding that a congressional district (state) receives. Research suggests that the president has political preferences over how federal funding is distributed (Berry et al., 2010; McCarty, 2000; Hudak, 2014; Kriner \& Reeves, 2015). In particular, Young and Sobel (2013) find that the president engages in distributive politics by allocating more funds towards areas with a high vote share as a way of paying voters back for their support. The president can also allocate more funds to strategic battleground states in order to increase his support in that area.

Furthermore, the president has a clear incentive to try to influence the distribution of federal grant spending in favor of members of his own party. Due to the separation of powers presidents cannot directly introduce legislation in congress, nor can they vote on legislation. Thus, presidents will turn to their partisan allies in Congress to further their legislative agenda. Indeed, research finds that the president has greater legislative support from members of his own political party than members of the opposing party, and that partisanship has a large effect over how members of congress vote (Barrett and Eshaugh-Soha, 2007; Ferguson, 2003; Hager and Talbert, 2000; Middlemass and Grose, 2007). Furthermore, EshbaughSoha (2005) finds that partisan characteristics of Congress also affect the type 
of legislative agenda that the president proposes. Under a unified government presidents propose more major and incremental policies, while under a divided government presidents propose more short term policies that are not central to their interests. Thus, presidents have a clear incentive to try to maintain a unified government because this allows them to further a legislative agenda that is central to their political interests.

One tool that the president can use to help secure, or maintain, a unified government is distributive politics. The president may direct the flow of federal dollars towards aligned members of congress' district (state). As the number of federal dollars directed to the aligned member's district (state) increases this will lead to an increase in voter satisfaction (Dixit and Londregan, 1996). The increase in voter satisfaction should lead to an increase in the probability that the member of Congress is re-elected. Thus through distributive politics, the president can help secure support for aligned congress members and potentially decrease electoral support for dis-aligned congress members.

\subsection{The Budget Appropriations Process}

Although the president has an incentive to influence the flow of federal grant dollars toward aligned members' districts the question of how the president is able to exert this influence remains. Figure 3.1 displays a flow chart of the federal budget approval process. As this figure illustrates, the budget approval process starts in the executive branch. All federal agencies submit their budget recommendations to the president. The president then takes these recommendations into consideration and develops a federal budget proposal. Then the proposed budget is submitted to Congress.

Once the proposed federal budget has been submitted to Congress both chambers are tasked with creating the federal budget that will be implemented in the next fiscal year. The Senate and H.O.R. each pass a budget resolution. This 


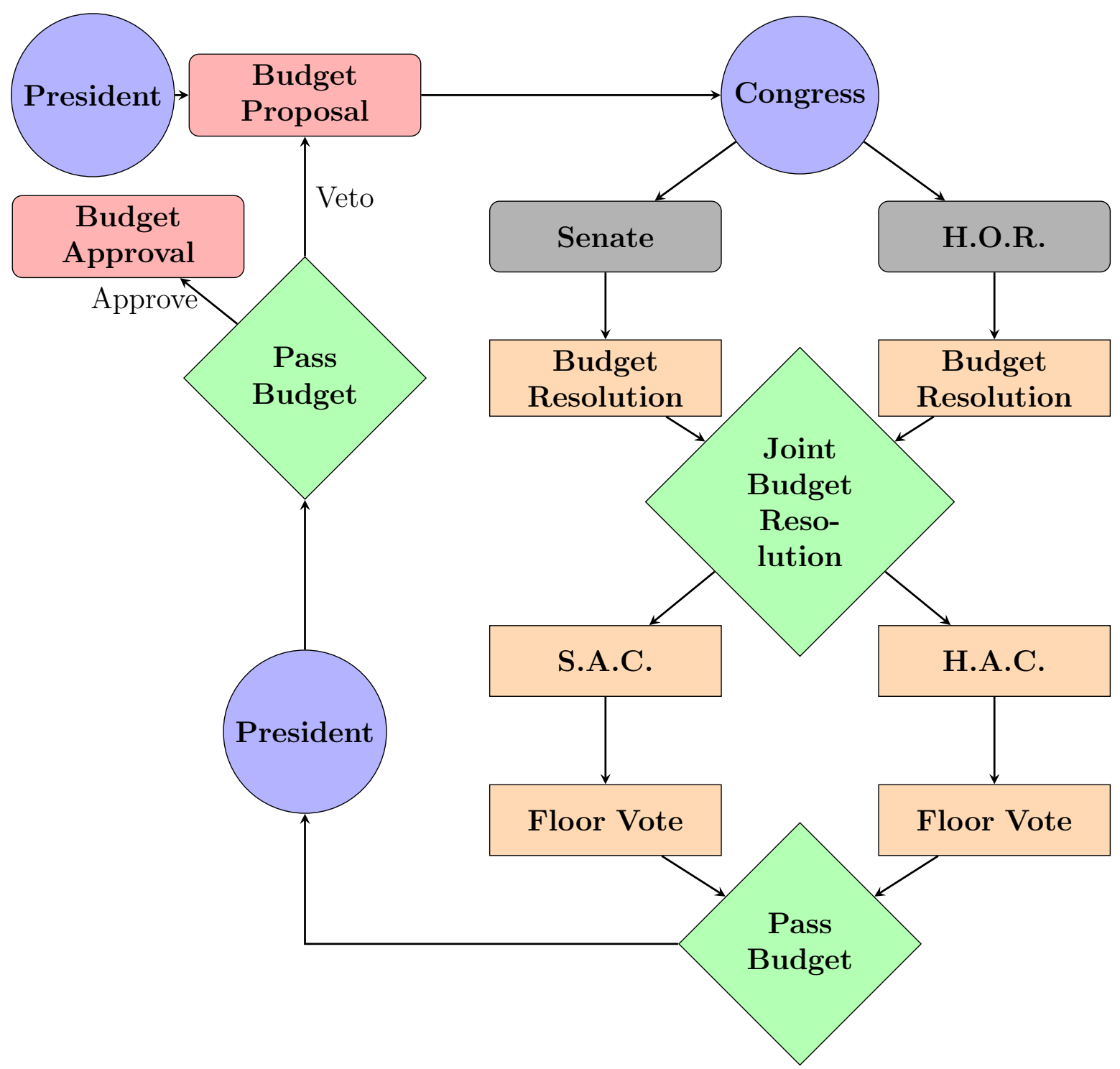

Figure 3.1: Budget Approval Process

resolution sets the federal spending limits and is written independently in both chambers. Once both chambers have written a budget resolution they come together in a joint committee and merge the two plans. After both the H.O.R. and Senate have agreed on a budget resolution both chambers must pass the identical resolution. Then the federal budget goes to the appropriations committees in each chamber. Once in committee twelve appropriations subcommittees in the H.O.R. and twelve appropriations subcommittees in the Senate are formed. These committees determine how to allocate the federal funds among all of the executive agencies. 
Prior to 2011, this was where congressional earmarking entered the budget appropriations process. Members of Congress would submit earmark spending requests to their respective committees. For example, if a representative wanted to earmark transportation funds to build a bridge in their district an earmark request would be submitted to the transportation committee. Then the Appropriations Committee would set the total budget available for earmarked projects. Each committee would then submit the earmark requests to the appropriations committee. Then the requests are either approved and added to the federal budget or denied (Sciara, 2012). However, after the enactment of the 2011 moratorium on earmarks Congress no longer has the power to explicitly allocate federal funds to a specific project (Doyle, 2011; White, 2015). Therefore, after the earmark moratorium, the House Appropriations Committee (H.A.C.) and Senate Appropriations Committee (S.A.C.) simply determine the federal budget for each agency and do not allocate project funding.

Once the budget has passed through the H.A.C. and S.A.C. it goes to both the H.O.R. and Senate floor for a vote. Both chambers must pass the same federal budget. Therefore, before the floor vote, the budget goes through a reconciliation process where any budgetary differences between the two chambers are reconciled. The senate requires a 60 vote majority in order to pass the budget (otherwise the proposed budget can be filibustered). After the proposed budget has passed the floor vote in both chambers it is sent back to the President.

The president can either approve the federal budget or veto the budget. If approved the president signs the federal budget into law and it is implemented. In the case of a presidential veto, the budget is sent back to Congress. Congress can override a presidential veto with a two-thirds majority vote in both chambers. However, this is extremely difficult to accomplish and Congress has overridden less than ten percent of all presidential vetoes (History, Art Archives, U.S. House of Representatives 2020). If there are insufficient votes to overturn the veto then Congress must make changes to the federal budget to secure the president's sup- 
port.

\subsection{Presidential Influence}

As previously mentioned, the president can influence the budget approprations process by using either ex-ante or ex-post powers (Berry et al., 2010). The president's ex-ante power is derived from the president's ability to propose a federal budget to congress. Research on noncooperative bargaining games finds that the ability to propose a distribution of benefits gives the proposer considerable influence over how the benefits are divided up (Knight, 2005; Yildirim, 2007; Albouy, 2013; Berry et al., 2010). Furthermore, the ability to propose a federal budget allows the president to frame the budget debate in Congress, and include political objectives within the budget proposal. Lastly, the president can veto any budget that conflicts with his interests. This allows presidents with strong spending preferences to reject unfavorable spending bills (McCarty, 2000).

Ex post power primarily takes the form of the president's influence over the bureaucracy. Hudak (2014) notes that the president has a large amount of influence over the distribution of federal agency grant funds. The president can influence which projects get competitive grant funding by appointing cabinet secretaries. Cabinet secretaries make the final decision about which applicants receive grant funding. Thus the president can appoint cabinet secretaries that will fund projects that are consistent with his interests. Berry et al. (2010) also note that the president can repurpose some budgetary accounts. The president can also transfer funds between accounts; however, this action must be approved by Congress. Examples of ex post influence include the Bush administration's Faith-Based Initiative that created a new agency to provide grants to religious communities (Farris et al., 2004), the Obama administration's TIGER program that provided transportation grants to primarily urban areas, and the Trump administration shifting the TIGER program goals to prioritize rural communities (Scheck and Busche, 
2019; Lightman and Wieder, 2019).

Thus, the president has considerable influence over the appropriations process both before the federal budget has been passed and after it has been enacted. The president also has an incentive to allocate more distributive benefits to aligned members of Congress. This allows the president to help aid legislative allies' electorally and pay members of Congress back for their support. Therefore, the hypothesis is as follows: congressional districts (states) that are represented by aligned members of Congress will receive a higher portion of annual competitive grant funding than congressional districts (states) that are not represented by aligned members of Congress. 


\section{Chapter 4}

\section{Data Description}

The data for grant funding was gathered from USAspending.gov. USAspending.gov is the U.S. government's official database on federal spending. It contains data on all grants funded by the federal government and their funding amount over the time period of 2001-2017, at the recipient level. The data was aggregated to the congressional district level in order to ascertain the importance of political alignment to grant funding.

Only competitive grants awarded to state and local governments are considered in this analysis. The database consists of 3,526,955 awarded grants. This amounts to approximately $\$ 1.384$ trillion in competitive grant funding, with an average of $\$ 392,672.50$ per grant and a standard deviation of $\$ 9,191,606$. Following Gordon's (2018) methodology only grants issued to state and local governments were examined. ${ }^{1}$

After removing the nongovernmental grants and the grants with negative funding values ${ }^{2}$ the dataset consists of 672,861 competitive grants. The funding values

\footnotetext{
${ }^{1}$ Gordon notes that including grant issued to nonprofits and firms may produce miss leading results because the area where a firm is headquartered may not be in the same congressional district as where the work was carried out. Education grants were also excluded because these funds are often given to state capitals to distribute to school districts throughout the rest of the state.

${ }^{2}$ One complication with the annual grant funding variable is that it is mathematically possible for the total grant dollars that a congressional district receives in a given year to be negative. This problem arises because funds are allocated to a district in year $t-1$ to complete a project. However, if there are excess funds after the project is completed the funds are returned to the federal government in year $t$. These excess funds are recorded in the data as negative values for the year $t$. Therefore, for a small portion of the observations, the excess funds returned
} 
range from $\$ 0.00$ to $\$ 2.33$ billion, with a mean of $\$ 807,000$ and a standard deviation of $\$ 9,097,130$. The removal of the nongovernmental grants and grants with negative funding created a large amount of implicitly missing observations. Table 4.1 displays the number of implicitly missing congressional districts for every year in the sample. There are a total of 576 implicitly missing congressional districts across all years in the dataset, which amounts to $7.78 \%$ of the total observations. It is assumed that these districts are implicitly missing because they did not receive any competitive grant funding that year. Therefore, zero federal grant dollars was entered for all implicitly missing congressional districts. ${ }^{3}$

Table 4.1: Implicitly Missing Congressional Districts

\begin{tabular}{cc}
\hline \hline Year & Missing Districts \\
\hline 2001 & 158 \\
2002 & 172 \\
2003 & 173 \\
2004 & 15 \\
2005 & 19 \\
2006 & 22 \\
2007 & 0 \\
2008 & 4 \\
2009 & 0 \\
2010 & 0 \\
2011 & 0 \\
2012 & 7 \\
2013 & 2 \\
2014 & 0 \\
2015 & 0 \\
2016 & 0 \\
2017 & 4 \\
\hline Total & 576 \\
\hline \hline
\end{tabular}

to the federal government in year $t$ was greater than the total amount of competitive grant funding that the district received in year $t$. Thus leading to a negative value for the total grant funding variable when the data was aggregated to the congressional district level. Since these negative values have no reasonable interpretation all observations with negative funding amounts were excluded from the analysis. There were only 26 observations with negative values, which amounts to $0.3515 \%$ of the sample. A detailed description of how the grant data was aggregated from the project level to the congressional district level is available in the appendix.

${ }^{3}$ As a robustness check this assumption was tested by rerunning all of the analysis in the next two chapters with all implicitly missing observations excluded for the data set. The exclusion of implicitly missing observations did not change any of the results. Therefore, these finding have not been reported. 


\subsection{Political Control Variables}

Fifteen additional political control variables will be included in the analysis. First, research has found that the appropriations committees play a major role in distributive politics in both chambers of government (Berry et al., 2010; Clemens et al., 2015a; Lazarus and Steigerwalt, 2009). Therefore two dichotomous control variables will be included in the analysis: H.O.R. Appropriations and Senate Appropriations. The H.O.R. appropriations variable was coded as a one if the district was represented by someone who sat on the appropriations committee, and zero otherwise. The senate appropriations variable was coded as one if the state had at least one Senator that sat on the appropriations committee and zero otherwise. Following Berry et al. (2010) a dichotomous variable to control for a representative siting on the ways and means committee in the H.O.R. was also included in the analysis. This variable is called H.O.R. Ways and Means.

There is also some evidence that a representative's position on the committee influence the amount of federal grant funding that they receive (Berry et al., 2010; Clemens et al., 2015a). Three variables were included in the analysis to control for this H.O.R. Committee Chair, H.O.R. Ranking Member and H.O.R. First Term. Committee Chair is a dummy variable that was coded as one if the representative serves as a committee chair on at least one committee and zero otherwise. Ranking member is a dummy variable that was coded as one if the representative served as a ranking member of the minority on at least one committee and zero otherwise. Lastly, first term is a dummy variable that is coded as one if it is the representative's first term in office and zero otherwise.

Next, two dummy variables were included that indicate if the district was represented by a party leader; H.O.R. Party Leader and Senate Party Leader. The H.O.R. party leader variable was coded as one if the representative was the majority party leader or minority party leader, and zero otherwise. The senate variable was coded in the same manner. Although Lazarus and Steigerwalt (2009) 


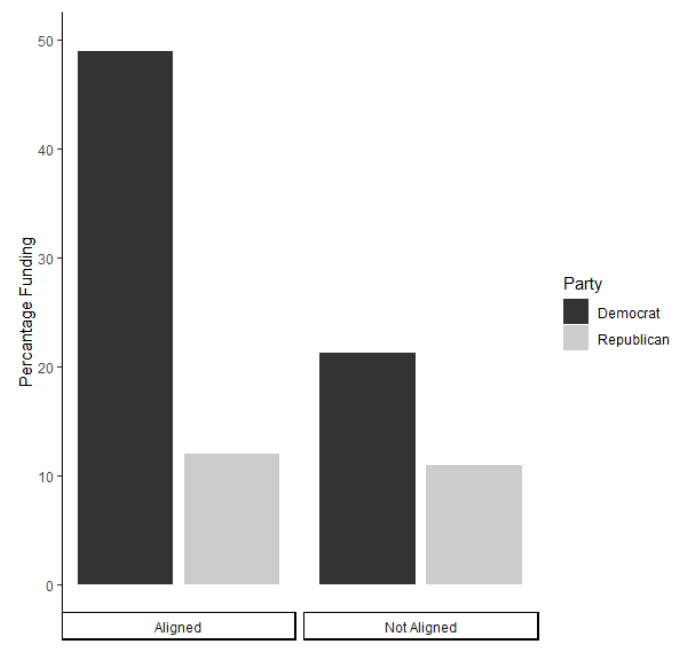

(a) Senate

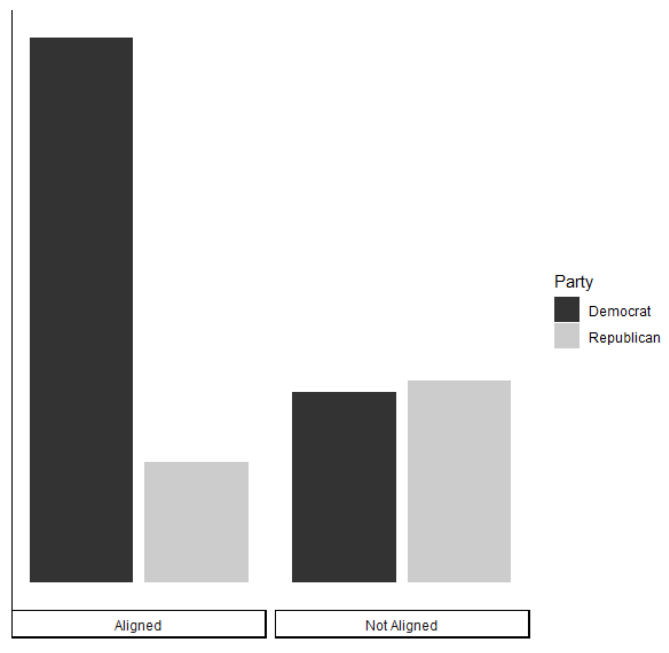

(b) House of Representatives

Figure 4.1: Portion Of Total Grant Funding by Partisanship

found that party leadership was only significant in the H.O.R., it still may be an important factor to control for because party leaders may be able to utilize their political power to secure more funding and one of them is necessarily aligned with the president. Furthermore, the president may allocate more funding to party leaders, regardless of their alignment, in order to purchase their support for key pieces of legislation.

The next set of control variables will indicate if the district was represented by a democrat, H.O.R. Republican and Senate Democrat. H.O.R. Republican is coded as one if the representative is a Republican and zero otherwise. Senate Democrat is coded as one if the representative is a Democrat and zero otherwise. This variable is included in the analysis because research has found that Democrats tend to receive a higher portion of distributive spending (Alvarez and Saving, 1997), and this trend is also persistent in the data as demonstrated by figure 4.1. Data for all of these variables was collected from the Charles Stewart Committee Assignment data set (Stewart, 2017).

Three electoral variables will also be included in the analysis: President Vote Share, Representative Vote Share, and Senator Vote Share. There is reason to believe that the president may want to allocate funds strategically in order to maximize his votes (Berry et al., 2010). Thus, the portion of votes that the 
president received in state $i$ is also included in the analysis to control for the electoral importance of the state. In years where a presidential election did not take place, this variable is coded as a zero. The representative vote share variable controls for the electoral vulnerability of the representative. Past research has demonstrated that vulnerable members tend to receive more distributive benefits (Lazarus, 2009; Lazarus and Steigerwalt, 2009). This variable is the share of votes that the representative received. In years where there was not an election, it is coded as zero. Lastly, the senator vote share variable is the share of votes that the senator received in the last election. If an election did not occur this variable is coded as zero. Data for these variables was collected from the MIT Election Data set (MIT Election Data, 2017).

Two additional variables to control for majority party status in both chambers were also included in the analysis. There is a wide range of evidence suggesting that members of the majority party receive a larger portion of funds (Berry et al., 2010; Lazarus and Steigerwalt, 2009; Albouy, 2013). To control for a district being located in a state where both Senators are members of the majority party Two MP Senators was included in the analysis. Two MP senators is a dichotomous variable that is coded as a one if both of the state's senators are in the majority party and zero otherwise. To control for a district being represented by a member of the H.O.R. which belongs to the majority party H.O.R. Majority Party dummy was included. The data for both of these variables was collected from Charles Stewart Committee Assignment data sets.

\subsection{Socioeconomic Control Variables}

Four socioeconomic variables were also added to control for the socioeconomic character of the state. It must be noted that the data for all four of these variables was collected from the Census, and Bureau of Economic Analysis (B.E.A.). Thus these variables are measured at the state level, not the congressional district level. 
The first socioeconomic variable is government workers. This is the total amount of jobs working for the state or local government in a given state divided by the labor force. Since the outcome variable only examines grants awarded to state and local governments, states with a large public sector may receive a higher portion of funds because they have a higher need for intergovernmental grants. Therefore, the government workers variable was included to control for the size of the public sector and the demand for funding. Unemployment Benefits also controls for both the size of the public sector and the state's demand for grant dollars. States with a large number of unemployment benefits may require more assistance from the federal government because they have a high amount of expenditures and potentially a smaller tax base. The data for both of these variables was collected from the B.E.A.

The next set of socioeconomic control variables were collected from Census population estimates and control for a state's demographic factors. The first variable is Percent Poverty. Percent in poverty measures the portion of a state's population that is living in poverty. States with a high percentage of the population living in poverty may receive more federal grant dollars as a form of economic relief to increase living standards. The last variable is minority. This variable is the total amount of nonwhite residents living in a state divided by the state's population. This variable is included to control for other demand side factors such as programs designed to help minority populations. There may be grant programs specifically designed to target minorities. Thus states with a large minority population would receive a larger share of those funds (U.S. Census Bureau, 2020).

\subsection{Descriptive Statistics}

Figure 4.2 displays a heat map of the continental U.S. for each year in the time period of 2002 to 2017. The year 2001 was not included in the figure because the census TIGER congressional district shapefiles were not available for 2001. In 
figure 4.2 the shading indicates the quantile of the percentage of annual competitive grant funding that each congressional district was located in. Lighter shading indicates that the congressional district received a higher percentage of annual grant funding that year. The points located at the center of each congressional district indicate if the district was aligned with the president.

This figure demonstrates that larger districts receive a higher percentage of annual competitive grant funding, regardless of alignment status. At-large states such as Montana and Wyoming are always located in the top quantile of annual competitive grant funding, while the percentage of annual competitive grant funding that smaller aligned districts receive trends to fluctuate from year to year. Another, important geographic pattern revealed by figure 4.2 is that districts located on the west coast tend to receive a larger percentage of annual competitive grant funding. This may be due to the fact that there is more federal public land located in the western region of the U.S., thus more federal grant dollars are allocated to this region in order to help maintain the federal land.

Table 4.2 displays the average amount of funding per grant for every year in the sample. In order to allow for a year to year comparisons, the funding values are reported in 2018 U.S. dollars. The states and congressional districts that received the lowest level of per grant funding and the highest level of per grant funding are also displayed in Table 4.2. This table demonstrates that there is a high level of variance in average per grant funding across states, congressional districts, and years. The mean difference in average per grant funding between the maximum state and minimum state across all 17 years is $\$ 8,019.45$. With regard to congressional districts, the mean difference between the maximum and minimum district across all 17 years is $\$ 125,890.38$. Thus there is considerably more variance in the level of per grant funding at the congressional district level than at the state level.

Figure 4.3 displays how the distribution of the portion of annual grant funding a district receives changes with aligned and dis-aligned members of the H.O.R on a 


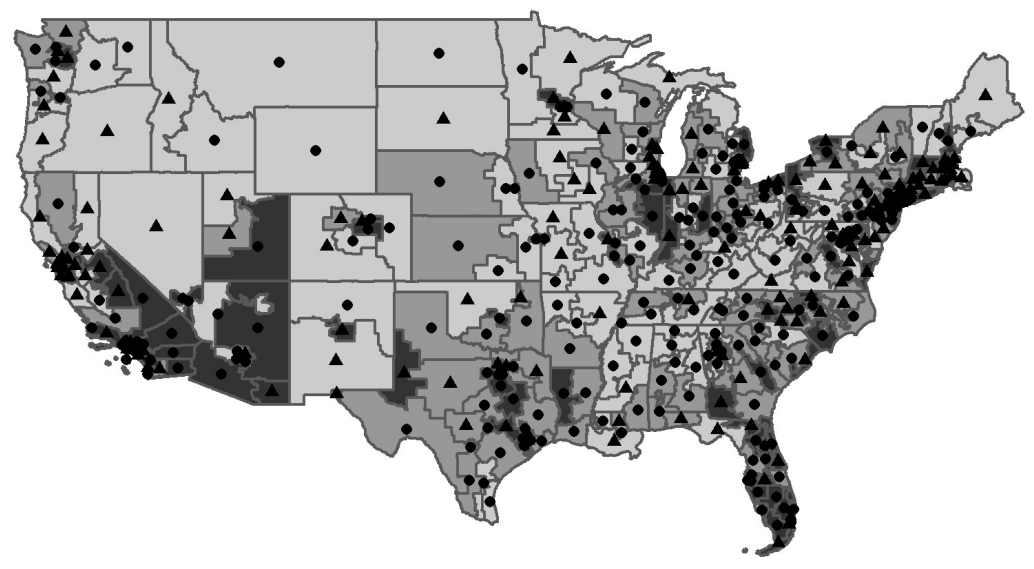

Alignment

- Aligned

- Not Aligned

Percent Funding

6.0724-0.1548 0.1548-0.0296 0.0296-0

(a) 2002
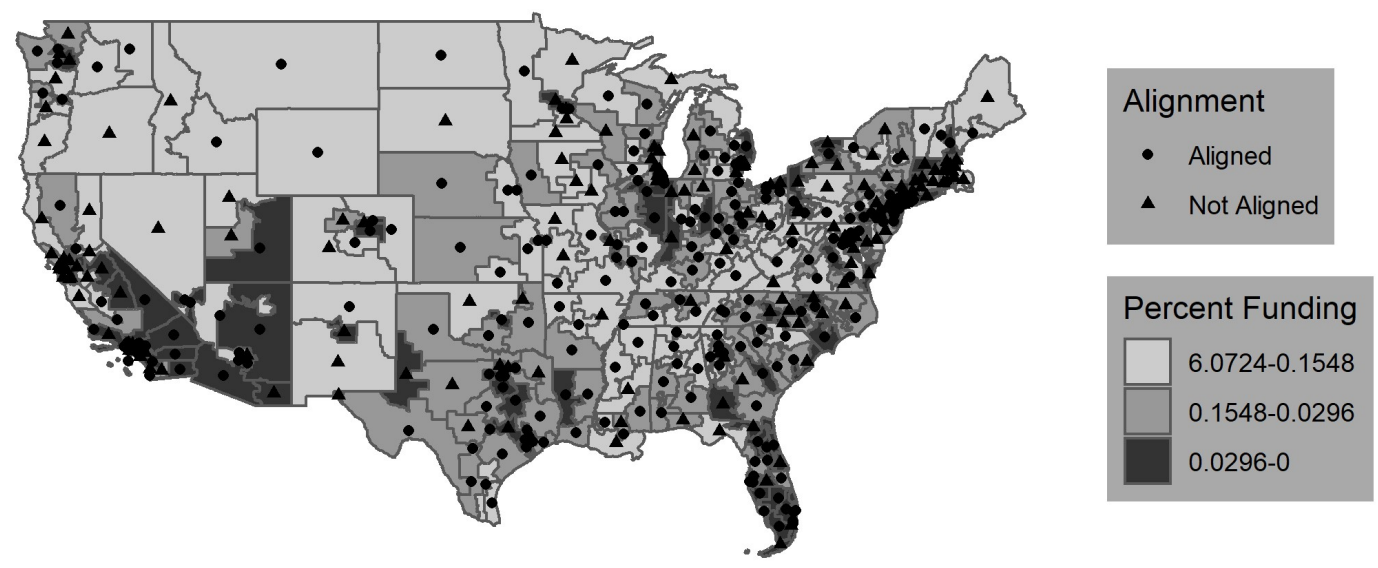

(b) 2003

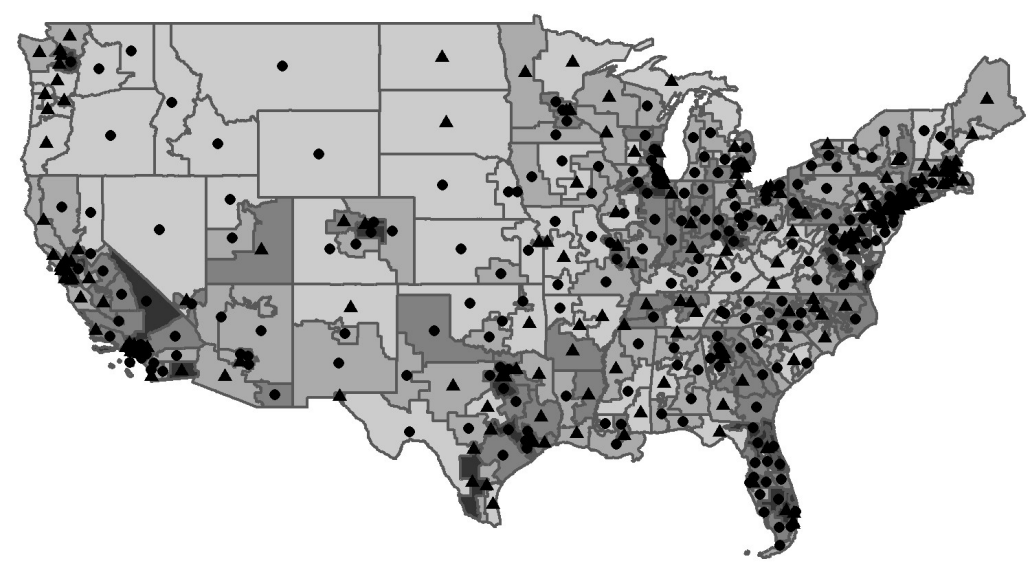

Percent Funding

7.7022-0.1475 0.1475-0.0531 0.0531-0.0144 $0.0144-0$

Alignment

- Aligned

- Not Aligned

(c) 2004 


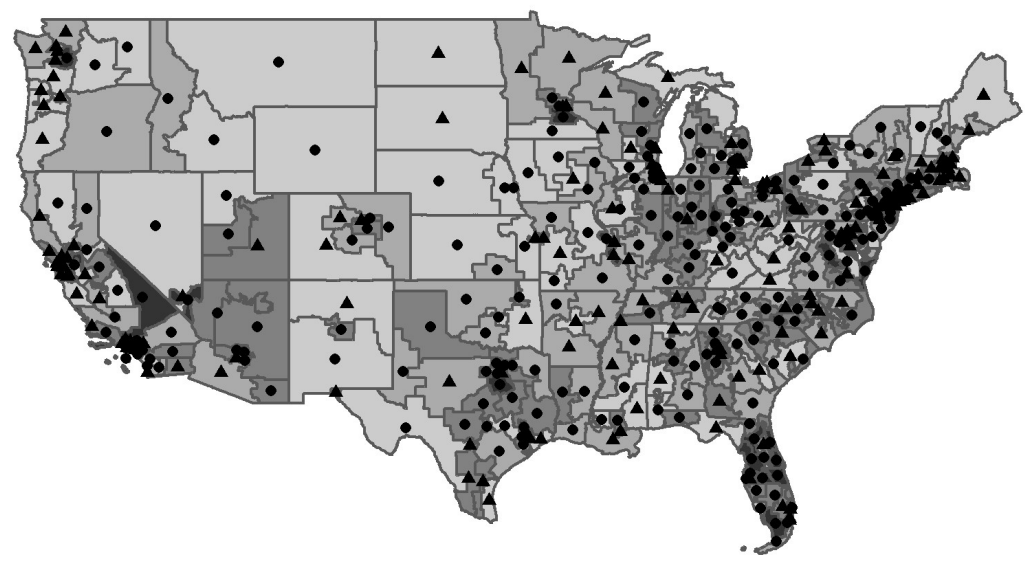

Percent Funding

$\square$ 7.5788-0.1663 0.1663-0.0601 $0.0601-0.0134$ $0.0134-0$

Alignment

- Aligned

- Not Aligned

(d) 2005

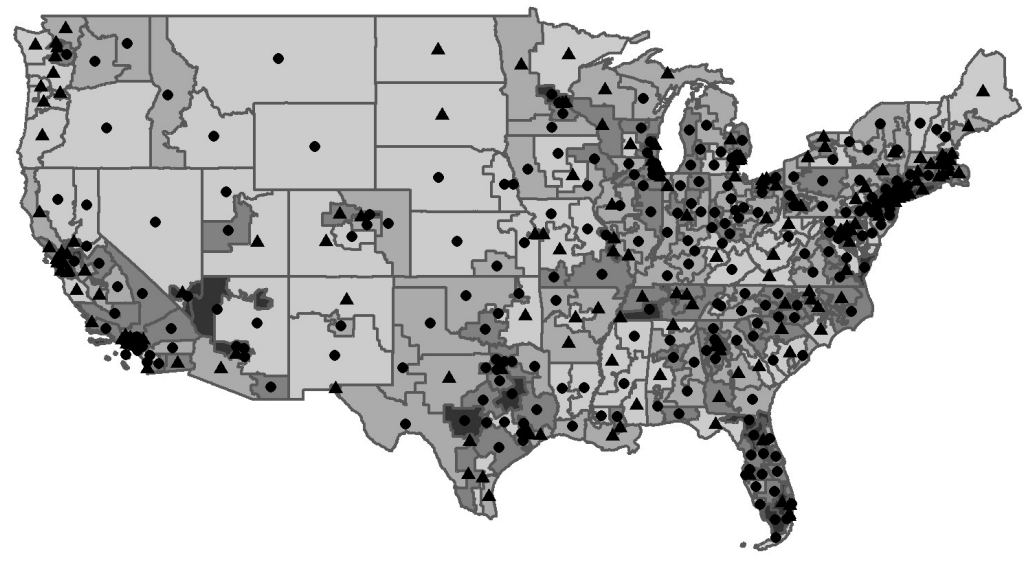

Alignment

- Aligned

- Not Aligned

Percent Funding

\begin{tabular}{|l|l|}
\hline & $8.4731-0.1437$ \\
\hline$\square$ & $0.1437-0.061$ \\
\hline$\square$ & $0.061-0.0144$ \\
$0.0144-0$
\end{tabular}

(e) $\mathbf{2 0 0 6}$

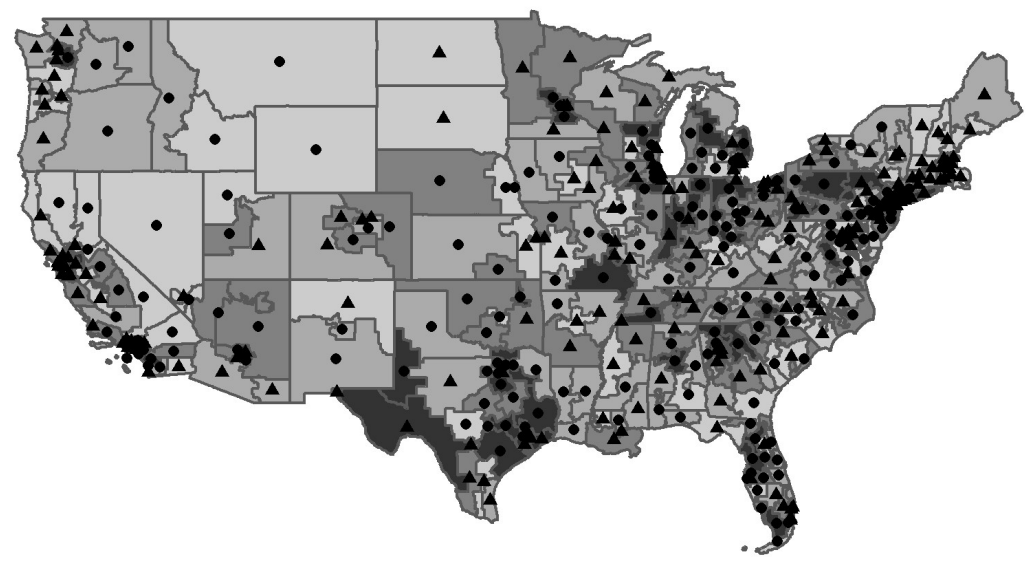

Alignment

- Aligned

- Not Aligned

Percent Funding

3.9218-0.194 0.194-0.0706 0.0706-0.0316 $0.0316-3 e-04$

(f) 2007 

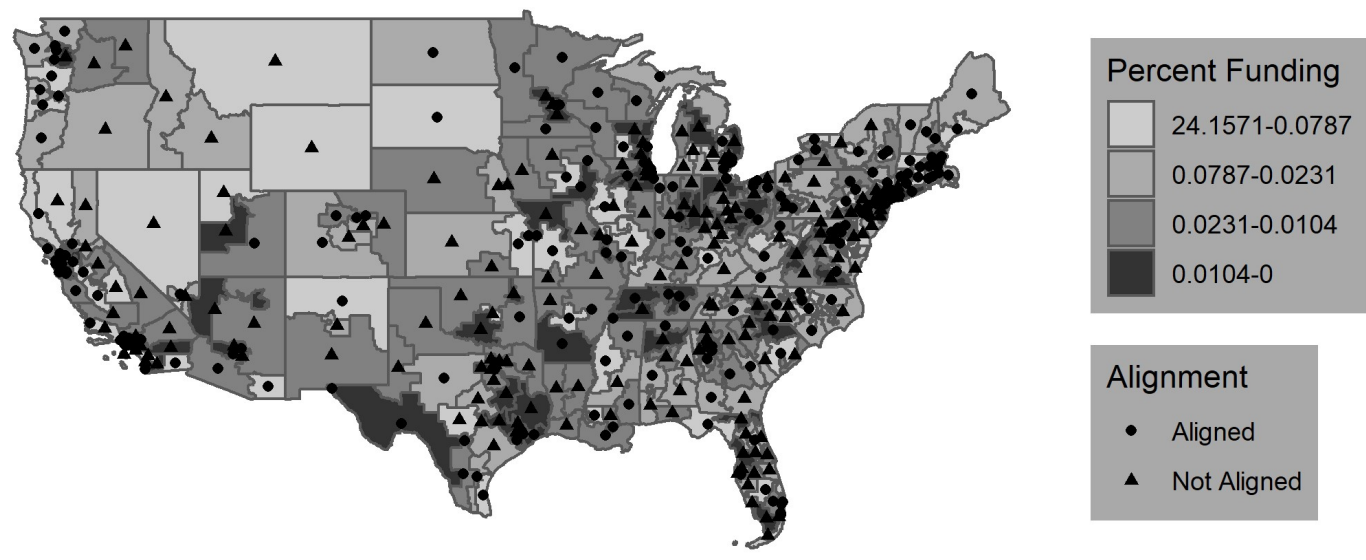

(g) 2008
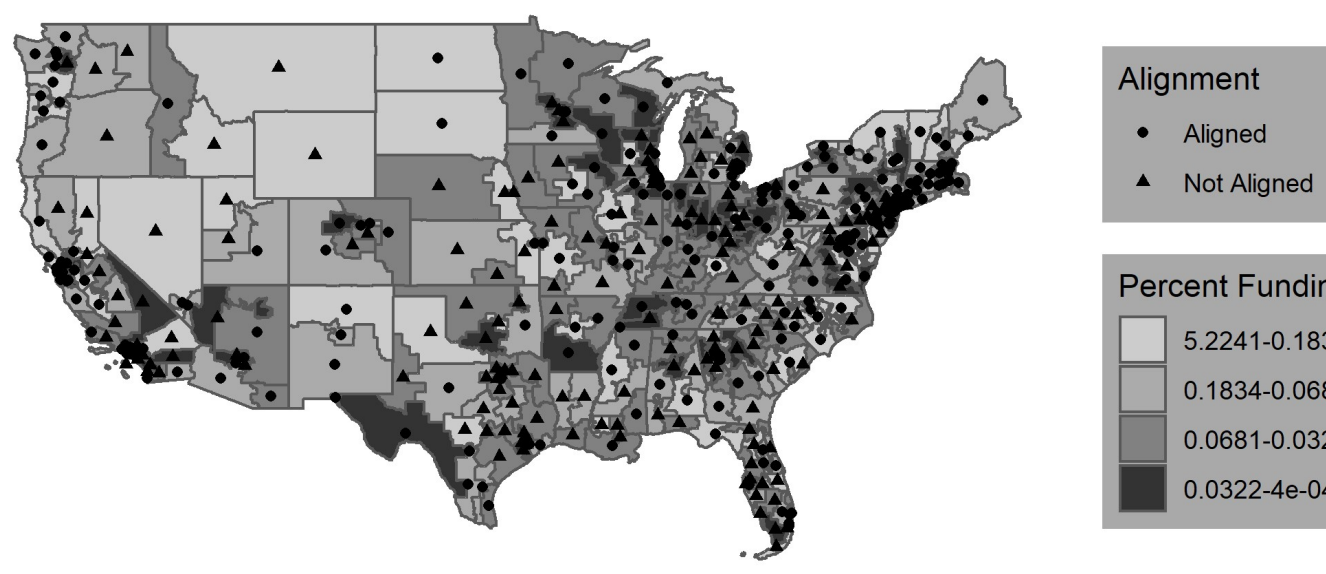

(h) 2009

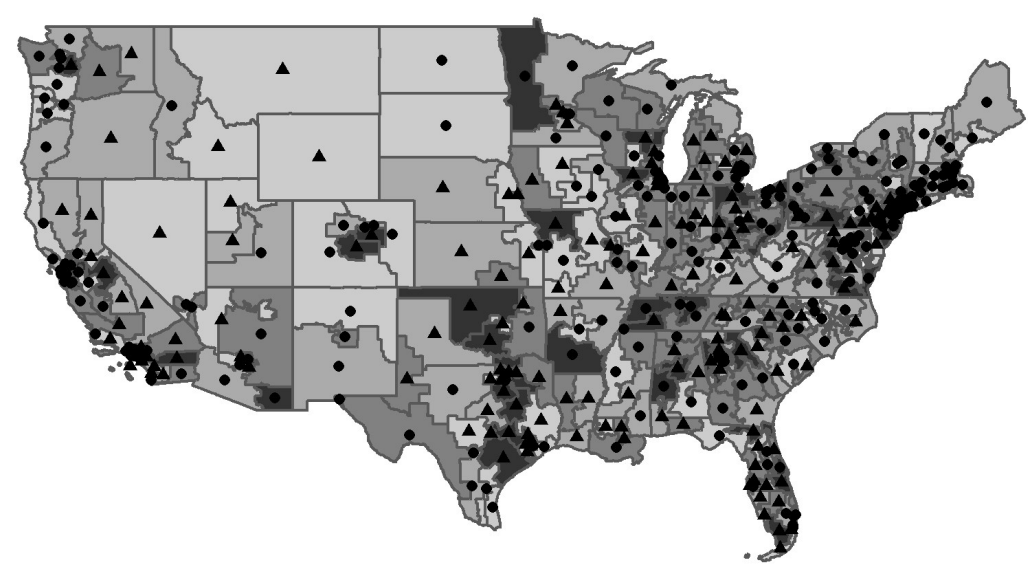

Percent Funding 5.8424-0.1802 0.1802-0.0564 0.0564-0.0265 0.0265-0.001

Alignment

- Aligned

- Not Aligned

(i) $\mathbf{2 0 1 0}$ 


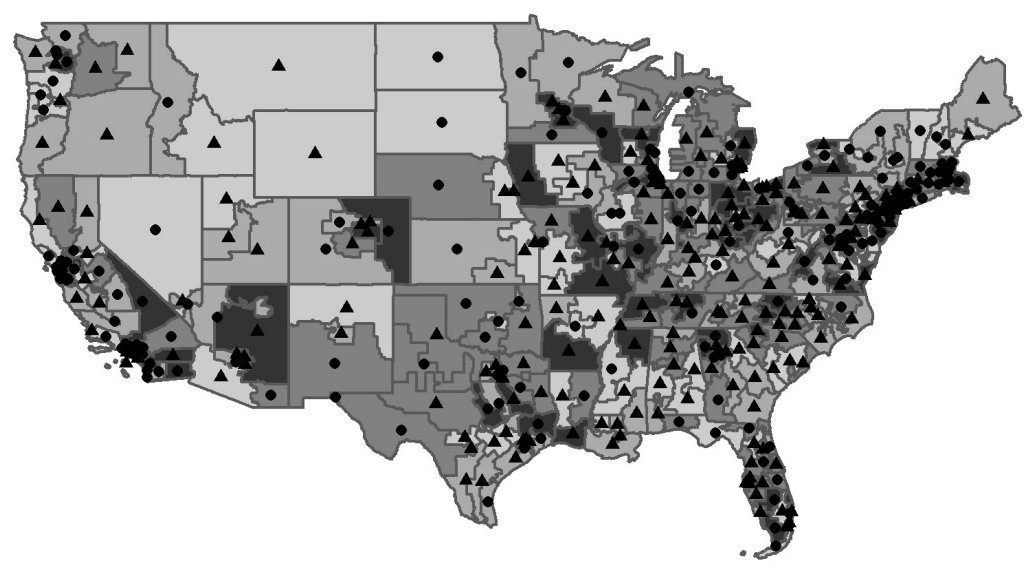

Percent Funding

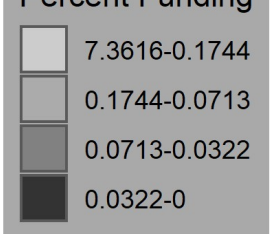

Alignment

- Aligned

- Not Aligned

(j) 2011

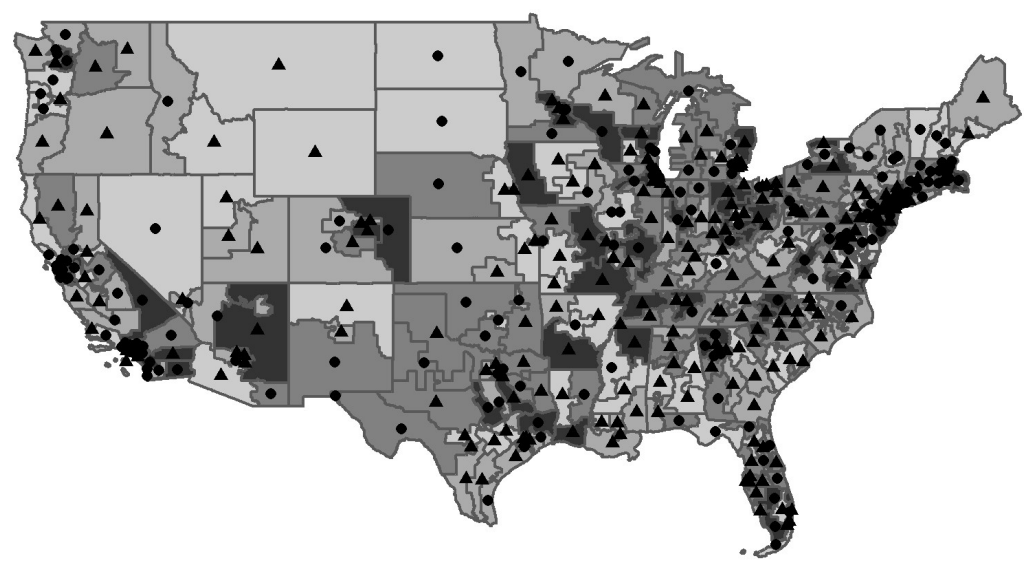

Percent Funding

7.3616-0.1744 0.1744-0.0713 0.0713-0.0322 $0.0322-0$

Alignment

- Aligned

- Not Aligned

(k) 2012

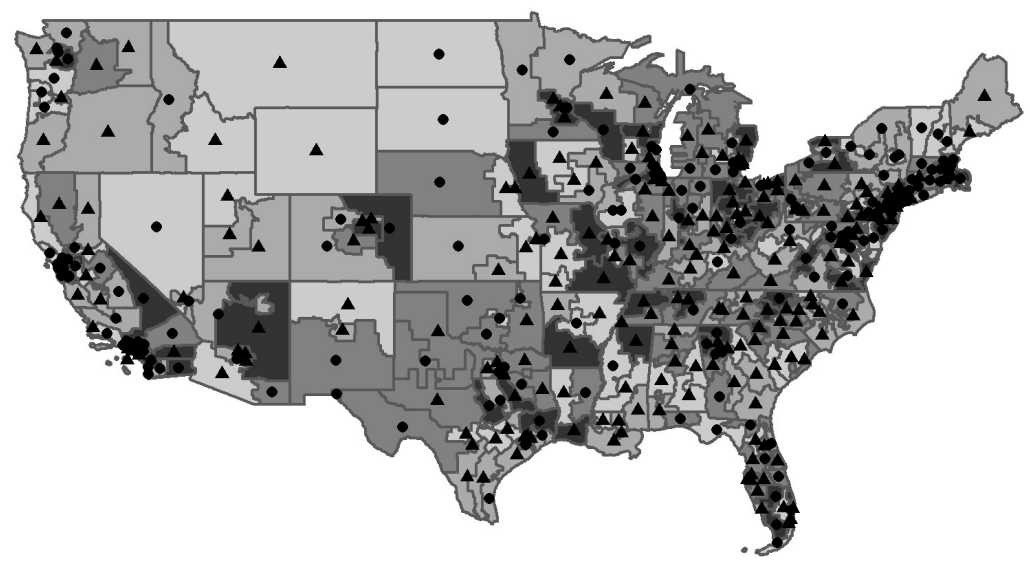

Percent Funding

7.3616-0.1744 0.1744-0.0713 0.0713-0.0322 $0.0322-0$

Alignment

- Aligned

- Not Aligned

(1) 2013 

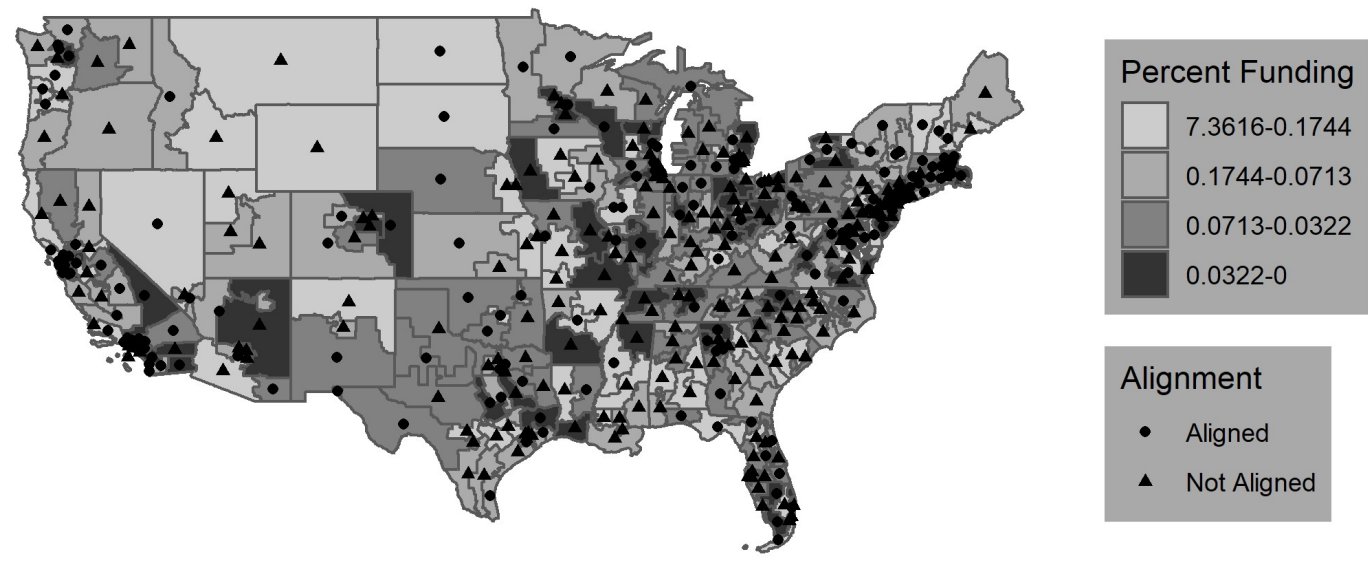

(m) 2014
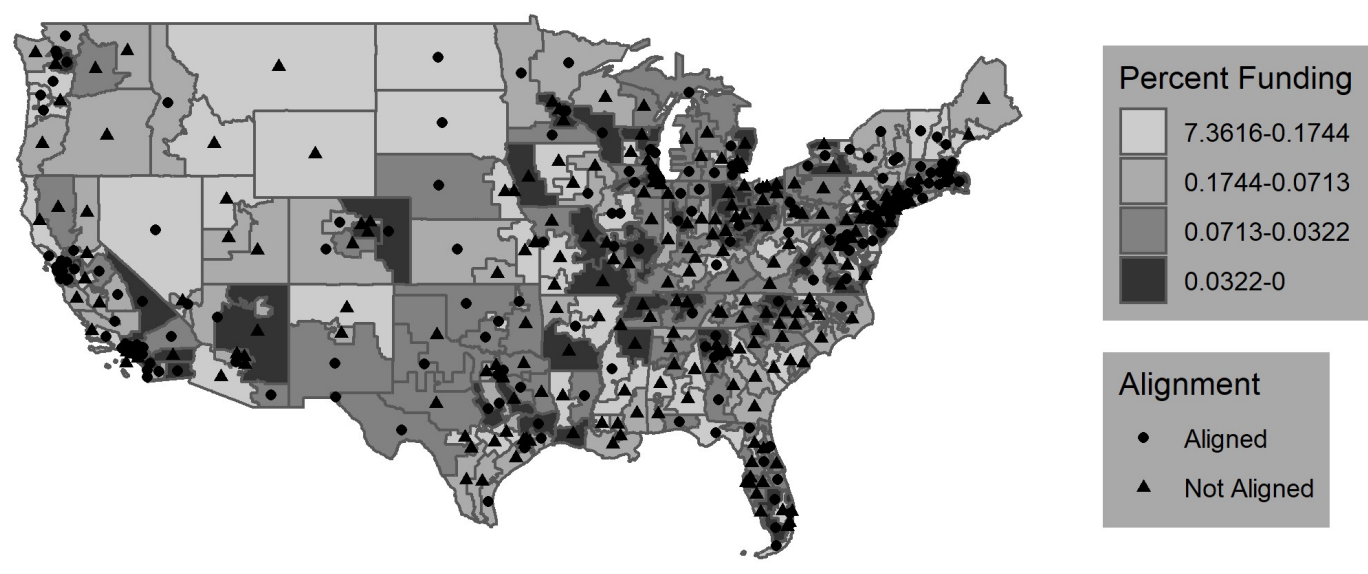

\section{Alignment}

- Aligned

- Not Aligned

(n) 2015

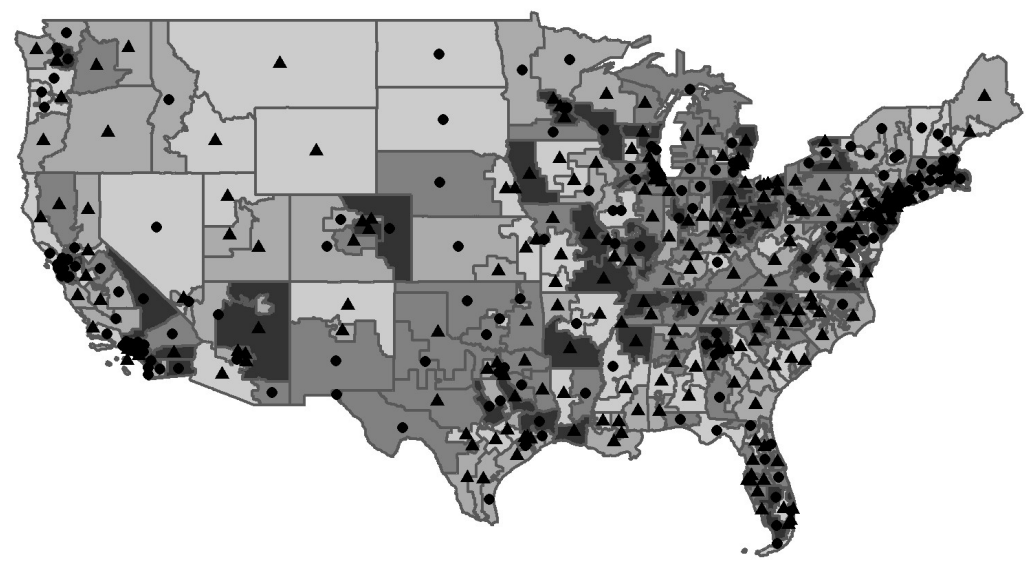

Percent Funding 7.3616-0.1744 0.1744-0.0713 0.0713-0.0322 0.0322-0

Alignment

- Aligned

- Not Aligned

(o) 2016 

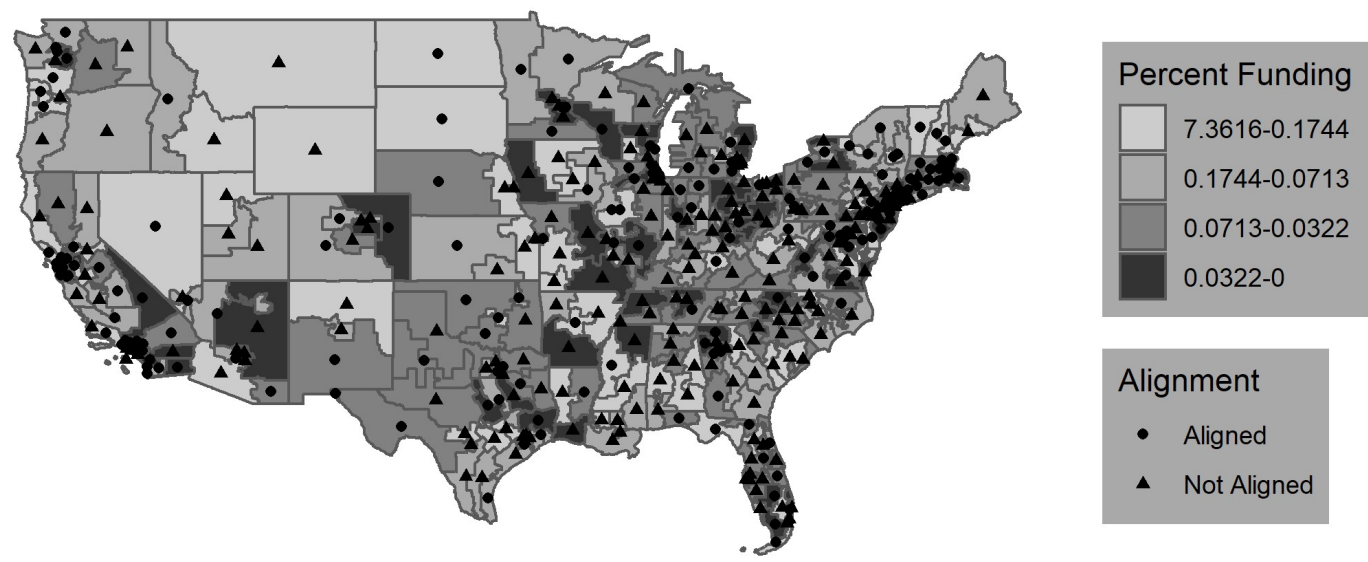

(p) 2017

Figure 4.2: Geographic Distribution of Funds and Alignment: 2002-2017

logged scale. This figure demonstrates that there are more aligned districts in the data set than dis-aligned districts. Furthermore, the measure of central tendency of the portion annual grant funding is slightly larger in the aligned district. The median portion of annual grant funding for aligned districts is $0.06 \%$, while the median portion of annual grant funding for dis-aligned districts is $0.05 \%$.

Table 4.3 displays the results from a difference of means test performed on all variables in the data set. The results demonstrate that the average percentage of competitive grant funding that aligned districts received was slightly greater than the percentage of annual grant funding allocated to dis-aligned districts. However, the p-value suggests that these differences are not statistically significant at any level. The difference of means tests also revealed some differences in the characteristics of aligned and dis-aligned districts. A larger portion of dis-aligned districts were represented by Democrats in the H.O.R., and on average were located in states with a larger percentage of the population living in poverty. A larger portion of aligned districts were represented by members of the majority party in the H.O.R. More aligned districts were also located in states where both senators were members of the majority party and on average had higher levels of unemployment benefits than dis-aligned districts. 


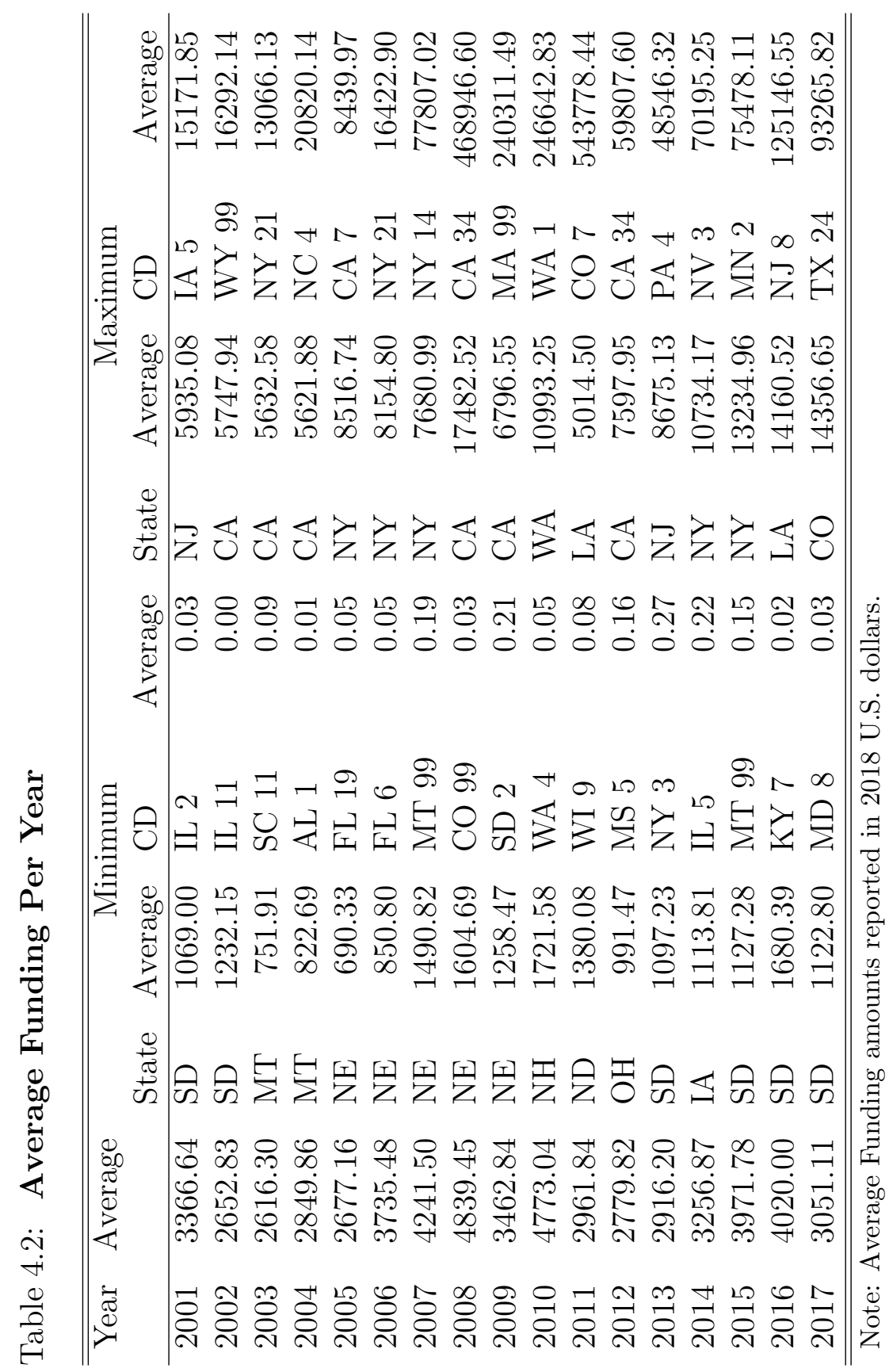




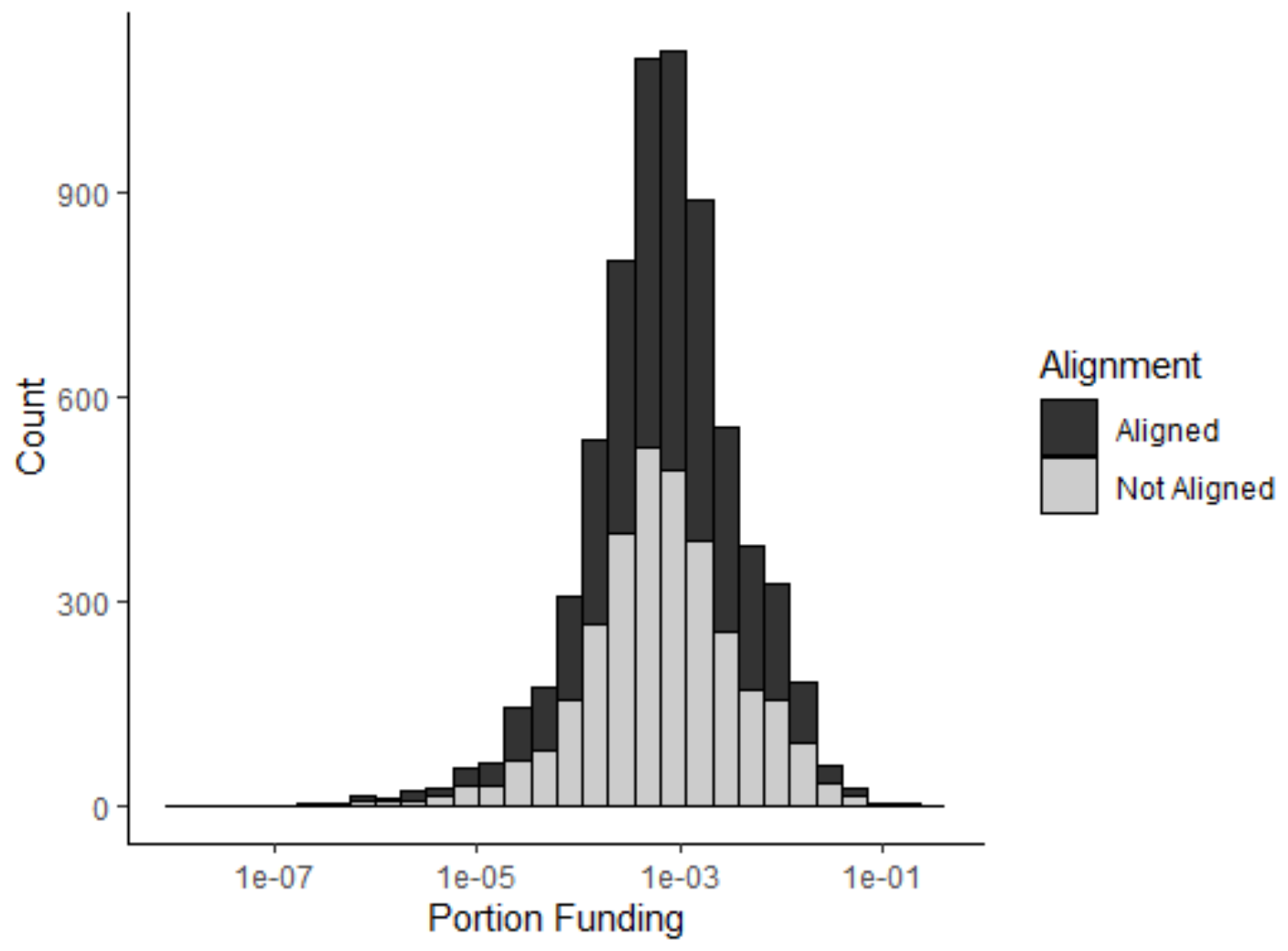

Figure 4.3: Distribution of Portion of Grant Funding in Aligned and Dis-aligned Districts 
Table 4.3: Difference of Mean Test

\begin{tabular}{|c|c|c|c|}
\hline & Not Aligned & Aligned & $\overline{\overline{\text { Difference }}}$ \\
\hline \multirow{2}{*}{ Percent Funding } & 0.2274 & 0.2322 & -0.0004 \\
\hline & $(0.6461)$ & $(0.7966)$ & $(0.775)$ \\
\hline \multirow[t]{2}{*}{ Representative V.S. } & 0.3082 & 0.3134 & -0.0005 \\
\hline & $(0.3450)$ & $(0.3359)$ & $(0.514)$ \\
\hline \multirow{2}{*}{ H.O.R. Republican } & 0.4835 & 0.5416 & $0.0581^{* * *}$ \\
\hline & $(0.4998)$ & $(0.4983)$ & $(0.000)$ \\
\hline \multirow[t]{2}{*}{ H.O.R. Majority Party } & 0.4010 & 0.6886 & $-0.0287^{* * *}$ \\
\hline & $(0.4902)$ & $(0.4631)$ & $(0.000)$ \\
\hline \multirow{2}{*}{ H.O.R. Party Leader } & 0.0047 & 0.0045 & 0.0000 \\
\hline & $(0.0687)$ & $(0.0667)$ & $(0.8602)$ \\
\hline \multirow[t]{2}{*}{ H.O.R. Appropriations } & 0.1341 & 0.1394 & -0.0005 \\
\hline & $(0.3408)$ & $(0.3464)$ & $(0.5094)$ \\
\hline \multirow[t]{2}{*}{ H.O.R. Ways and Mean } & 0.0903 & 0.0958 & -0.0054 \\
\hline & $(0.2867)$ & $(0.2943)$ & $(0.418)$ \\
\hline \multirow[t]{2}{*}{ H.O.R. Committee Chair } & 0.0407 & 0.0682 & $-0.0275^{* * *}$ \\
\hline & $(0.1976)$ & $(0.2522)$ & $(0.000)$ \\
\hline \multirow[t]{2}{*}{ H.O.R. Ranking Member } & 0.0666 & 0.0349 & $0.03173^{* * *}$ \\
\hline & $(0.2494)$ & $(0.1835)$ & $(0.000)$ \\
\hline \multirow[t]{2}{*}{ H.O.R. First Term } & 0.9838 & 0.9834 & 0.0003 \\
\hline & $(0.1261)$ & $(0.1275)$ & $(0.901)$ \\
\hline \multirow[t]{2}{*}{ President V.S. } & 0.1299 & 0.1323 & -0.0002 \\
\hline & $(0.2364)$ & $(0.2386)$ & $(0.6624)$ \\
\hline \multirow[t]{2}{*}{ Senator V.S. } & 0.1753 & 0.1837 & -0.0008 \\
\hline & $(0.2688)$ & $(0.2728)$ & $(0.1838)$ \\
\hline \multirow[t]{2}{*}{ Two MP Senators } & 0.3408 & 0.4765 & $-0.1357^{* * *}$ \\
\hline & $(0.4740)$ & $(0.4995)$ & $(0.0000)$ \\
\hline \multirow[t]{2}{*}{ Senate Democrat } & 0.7013 & 0.6894 & 0.0191 \\
\hline & $(0.4577)$ & $(0.4628)$ & $(0.2657)$ \\
\hline \multirow[t]{2}{*}{ Senate Party Leader } & 0.0290 & 0.0207 & $0.0008^{*}$ \\
\hline & $(0.1678)$ & $(0.1425)$ & $(0.02295)$ \\
\hline \multirow[t]{2}{*}{ Senate Appropriations } & 0.5293 & 0.5280 & 0.0001 \\
\hline & $(0.4992)$ & $(0.4993)$ & $(0.9095)$ \\
\hline \multirow[t]{2}{*}{ Gov. Workers } & 0.1266 & 0.1263 & -0.0003 \\
\hline & $(0.0156)$ & $(0.0159)$ & $(0.365)$ \\
\hline \multirow[t]{2}{*}{ Unemployment Benefits } & 2523.93 & 2844.07 & $320.14^{* * *}$ \\
\hline & $(3079.4125)$ & $(3794.6281)$ & $(0.0000)$ \\
\hline \multirow[t]{2}{*}{ Percent Poverty } & 13.4567 & 13.2018 & $0.2549^{* * *}$ \\
\hline & $(2.9858)$ & $(2.8660)$ & $(0.000184)$ \\
\hline \multirow[t]{2}{*}{ Minority } & 1.2067 & 1.2117 & 0.0050 \\
\hline & $(0.591)$ & $(0.584)$ & $(0.713)$ \\
\hline
\end{tabular}

Mean estimates reports standard deviation in parentheses and the differences of means test reports $\mathrm{p}$-value in parentheses. ${ }^{*} p<0.05,{ }^{* *} p<0.01,{ }^{* * *} p<0.001$ 


\section{Chapter 5}

\section{Methodology}

The dependent variable is bounded by zero and one OLS regression will misspecify the functional form of the model. This problem arises because linear regression estimates a constant relationship between the dependent variable and the independent variables. Thus it is possible to obtain fitted values that fall outside of the range of zero and one (Papke and Wooldridge, 1996; Kieschnick and McCukkiugh, 2003; Murteira and Ramalho, 2016). The most common approaches to modeling fractional outcome variables are beta regression, fractional logit, and fractional probit regression.

This analysis will use fractional probit regression for three reasons. First, Papke and Wooldridge (1996) note that in the beta distribution there is a zero probability that the outcome variable will take on a value of zero or one $(\operatorname{Prob}(x=$ $0)=0$ ). Therefore, if zero or one is in the domain of the outcome variable beta regression is not appropriate. As previously stated, there are observations of the portion of annual grant funding that are equal to zero. Thus beta regression is not appropriate. Second, Meaney and Moineddin (2014) find that beta regression can produce biased estimates if the mean of the dependent variable is near the boundary region of zero or one. Since the mean of the portion of annual grant funding is very close to zero in the sample (portion annual grant funding has a mean of 0.0022 ) the beta regression estimates may be biased.

Third, a fractional probit model was chosen over a fractional logit model to use 
panel data econometric techniques. Although Meaney and Moineddin (2014) find that in large samples of cross sectional data fractional logit produces unbiased estimates, Papke and Wooldridge (2008) find that fractional logistic regression can produce inconsistent estimates in the presence of serial correlation. Serial correlation is a common feature of panel data. Thus, fractional probit regression is the more appropriate model and will be the primary regression that is estimated.

Equation 5.1 displays the model that will be estimated. In Equation $5.1 \Phi(\cdot)$ is a link function that specifies the functional form of the conditional expectation function. The fractional probit models use the CDF of the normal distribution $(\Phi(\cdot))$ as the link function (Papke and Wooldridge, 1996). This allows the fractional probit model to produce fitted values that are bounded by zero and one.

$$
E\left[Y_{i, t+1} \mid \cdot\right]=\Phi\left(\beta_{0}+\beta_{1} \text { Aligned }_{i, t}+P^{\prime} \theta+D^{\prime} \gamma+\alpha_{i}+\tau_{t}\right)
$$

In Equation 5.1, Aligned is the Aligned dummy variable discussed in the previous section and $Y$ is the portion of annual competitive grant funding that a congressional district received in a given year. The competitive grant funding variable is lead forward one year, as recommended by Berry et al. (2010). This reflects the fact that the funds awarded in year $t$ were allocated from the budget in year $t-1$. Thus the political factors that are present in year $t-1$ should effect the distribution of grant funds because these are the factors that were present when the appropriation decisions were made.

The identification strategy will be similar to the approach adopted by Berry et al. (2010). Berry et al.'s identification strategy relies on the fact that changes in the alignment variable are the result of two independent sources of variation. First, the alignment variable may change as a result of a district electing a new representative, holding the office of the president constant. Therefore, holding the partisanship of the president constant, the model will estimate if a district experienced an increase in the portion of the annual competitive grant funding after the aligned member took office. Second, holding the partisanship of the repre- 
sentative constant alignment may change as a result of a change in the president. Allowing the model to estimate the change in the portion of annual competitive grant funding that a district receives as a result of a change in the partisanship of the president while holding the partisanship of the representative constant.

At the state level, there are a total of 96 changes in alignment. Holding the party of the president constant, 12 of the changes in alignment were the results of changes in the senator's partisanship. Hold the partisanship of the senator constant, 72 changes in alignment were the result of changes in the partisanship of the president. There is substantially more variation in alignment at the district level. There are a total of 1,792 instances of changes in partisan alignment. Holding the president constant, 922 of the changes in alignment were the results of changes in the partisanship of the representatives. Holding the partisanship of the representatives constant, 870 changes in alignment were the result of changes in the partisanship of the president.

In order to address any potentially unobservable time-invariant state idiosyncratic factors a vector of congressional district fixed effects will be included in the model. This is indicated by $\alpha_{i}$ in equation 5.1. Year fixed effects are also included to control for any confounding unobservable district invariant but time-variant factors. This is indicated by $\tau_{t}$ in equation 5.1 .

Several control variables will also be included in the model to account for potentially confounding political factors. In equation $5.1 P$ is a vector of all of the political control variables that were discussed in the data description chapter. These variables include Representative Vote Share, H.O.R. Republican, H.O.R. Majority Party, H.O.R. Party Leader, H.O.R. Appropriations, H.O.R. Ways and Mean, H.O.R. Committee Chair, H.O.R. Ranking Committee Member, H.O.R. First Term, President Vote Share, Senator Vote Share, Two MP Senators, senate Democrat, senate Party Leader, and senate Appropriations. These variables will be included in the model to control for all political factors that vary across districts and years which are theoretically correlated with the portion of grant 
funding that a district receives and alignment with the President. Lastly, $D$ in equation 5.1 is a vector of the socioeconomic factors that may influence a state's demand for competitive grant funding. These variables are Government Workers, Unemployment Benefits, Percent in Poverty, and Minority. 


\section{Chapter 6}

\section{Results}

Table 6.1 displays the results for the base model. The model displayed in column one of table 6.1 is my analysis of Berry et al.'s (2010) model for the entire sample. The only difference between this model and Berry et al.'s model is that the model in this analysis uses representative vote share and president vote share as electoral control variables, while Berry et al. utilized close election dummies. However, the findings in table 6.1 differ greatly from Berry et al.'s results. The results suggest that alignment is positively related to the portion of annual total grant funding that a district receives, however it is not statically significant at any level. It has an associated p-value of $0.975 .^{1}$

Column two of table 6.1 adds the senate control variables and socio-economic control variables. In order to conserve space the socio-economic control variables discussed in chapters four and five are omitted from all of the regression tables presented in this chapter. However, every regression presented in this chapter includes a vector of socio-economic factors. These factors are the following: government employees, unemployment benefits, percent in poverty, and minority. ${ }^{2}$

\footnotetext{
${ }^{1}$ It must be noted that the same model was estimated for the time period of 2001 to 2007 , the overlap period with Berry et al., however the results did not change. Therefore, they are not reported in table 6.1 .

${ }^{2}$ It must be noted that the socio-economic control variables be highly correlated with the size of a state. Therefore to address any multicollinearity concerns all of the regression reported in this section where re-estimated without the socio-economic control variables. However, the findings did not changes. Therefore, only the models with socio-economic control variables are reported as these are the more robust results.
} 
When the senate control variables and socio-economic control variables are added to the model alignment remains statically insignificant. The p-value slightly decreases to 0.890 . Furthermore, the sign of the coefficient associated with alignment changes direction. Lastly, column three of table 6.1 displays the results from a fractional probit regression. In the fractional probit model alignment remains statically insignificant and negatively related to competitive grant funding. Furthermore, the p-value is still very large with a value of 0.741 .

The null findings presented in table 6.1 may in part be explained by agency heterogeneity. Research finds that federal agencies are not homogeneous units and they distribute grant funding differently based on their ideology, the majority party in Congress, and the politicization if federal programs (Bertelli and Grose, 2009; Ting, 2012). Therefore, aggregating all federal agency grants into one variable may be problematic because it cannot account for political and institutional differences between federal agencies.

To examine if agencies respond differently to alignment with the president, a bivariate regression was performed on every agency in the sample. The portion of annual competitive grant funding from agency $i$ was regressed on alignment. The results are displayed as a sign chart in table 6.2. These findings suggest that federal agencies may indeed respond differently to alignment with the president. Of the 30 agencies in the sample seven had a positive but statically insignificant relationship with alignment, and 18 agencies had a negative but statically insignificant relationship with alignment. There was one agency, the Delta Regional Authority (D.R.A.), which had a negative and statically significant relationship with alignment.

Five federal agencies had positive and statically significant relationships with alignment. The five federal agencies with significant and positive relationship with alignment were Corporation for National and Community Service (C.N.C.S.), Department of Commerce (D.O.C.), Department of Housing and Urban Development (H.U.D.), National Science Foundation (N.S.F.), and Department of State 
Table 6.1: Alignment and Competitive Grant Funding

\begin{tabular}{|c|c|c|c|}
\hline & OLS & OLS & Fractional Probit \\
\hline \multirow[t]{2}{*}{ Alignment } & 0.00000670 & -0.0000276 & -0.0066898 \\
\hline & $(0.000218)$ & $(0.0001986)$ & $(0.0202542)$ \\
\hline \multirow[t]{2}{*}{ H.O.R. Majority Party } & 0.000130 & 0.0001266 & 0.034066 \\
\hline & $(0.000300)$ & $(0.0003043)$ & $(0.0312648)$ \\
\hline \multirow[t]{2}{*}{ H.O.R. Committee Chair } & 0.000817 & 0.0008106 & 0.115178 \\
\hline & $(0.000632)$ & $(0.0006295)$ & $(0.07036)$ \\
\hline \multirow[t]{2}{*}{ H.O.R. Ranking Member } & 0.000150 & 0.0001342 & 0.0362228 \\
\hline & $(0.000382)$ & $(0.0003842)$ & $(0.0536795)$ \\
\hline \multirow[t]{2}{*}{ H.O.R. Party Leader } & 0.0000733 & 0.0000868 & 0.035819 \\
\hline & $(0.000796)$ & $(0.000805)$ & $(0.1167047)$ \\
\hline \multirow[t]{2}{*}{ H.O.R. Appropriations } & 0.000499 & 0.000486 & 0.0446013 \\
\hline & $(0.000527)$ & $(0.0005248)$ & $(0.0509151)$ \\
\hline \multirow[t]{2}{*}{ H.O.R. Ways and Means } & -0.000811 & -0.0008201 & $-0.1120518^{*}$ \\
\hline & $(0.000442)$ & $(0.0004452)$ & $(0.0454719)$ \\
\hline \multirow[t]{2}{*}{ H.O.R. Republican } & $-0.000204^{* *}$ & $-0.0002126^{* *}$ & $-0.0276258^{* *}$ \\
\hline & $(0.0000641)$ & $(0.0000617)$ & $(0.0094219)$ \\
\hline \multirow{2}{*}{ H.O.R. First Term } & $-0.00611^{* *}$ & $-0.0054961^{* *}$ & -0.0837537 \\
\hline & $(0.00208)$ & $(0.0019564)$ & $(0.0750717)$ \\
\hline \multirow[t]{2}{*}{ H.O.R. Representative V.S. } & -0.000474 & -0.0004995 & -0.042585 \\
\hline & $(0.000941)$ & $(0.0009102)$ & $(0.1062145)$ \\
\hline \multirow[t]{2}{*}{ President V.S. } & 0.000709 & 0.0001707 & -0.0246506 \\
\hline & $(0.00221)$ & $(0.002204)$ & $(0.2949109)$ \\
\hline \multirow[t]{2}{*}{ Senate Alignment } & & 0.0000793 & 0.0248519 \\
\hline & & $(0.0001832)$ & $(0.0248158)$ \\
\hline \multirow[t]{2}{*}{ Senator V.S. } & & 0.0003541 & 0.0520975 \\
\hline & & $(0.000211)$ & $(0.0298951)$ \\
\hline \multirow[t]{2}{*}{ Two M.P. Senators } & & 0.0000569 & -0.0137701 \\
\hline & & $(0.0002081)$ & $(0.0231616)$ \\
\hline \multirow[t]{2}{*}{ Senate Democrat } & & -0.0001366 & -0.0638598 \\
\hline & & $(0.0003098)$ & $(0.0455014)$ \\
\hline \multirow[t]{2}{*}{ Senate Party Leader } & & 0.0000257 & 0.0169887 \\
\hline & & $(0.0009409)$ & $(0.1083819)$ \\
\hline \multirow[t]{2}{*}{ Senate Appropriations } & & 0.0001575 & 0.0331555 \\
\hline & & $(0.000199)$ & $(0.0287062)$ \\
\hline Socio-Economic Controls & No & Yes & Yes \\
\hline District FE & Yes & Yes & Yes \\
\hline Year FE & Yes & Yes & Yes \\
\hline \multirow[t]{2}{*}{ Constant } & $0.00846^{* * *}$ & $0.0056854^{*}$ & $-2.816866^{* * *}$ \\
\hline & $(0.00215)$ & $(0.0022078)$ & $(0.2779719)$ \\
\hline$N$ & 7394 & 7394 & 7394 \\
\hline $\operatorname{adj.} R^{2}$ & 0.0145 & 0.0166 & \\
\hline
\end{tabular}

Standard errors in parentheses clustered by congressional district.

${ }^{*} p<0.05,{ }^{* *} p<0.01,{ }^{* * *} p<0.001$ 
(D.O.S.). These five agencies appear to be susceptible to presidential influence while the rest of the agencies in the sample appear to be more insulated from presidential influence. In order to estimate that effect of alignment on agencies that have some degree of susceptibility to executive influence a new portion of competitive grant funding variable was created using only competitive grants funding from these five agencies. Since the new competitive grant funding variable accounts for agency heterogeneity all models estimated in the remainder of the paper will adopt this variable as the dependent variable. It must be noted that the same models were estimated using competitive grant funding from all federal agencies in the sample. However, for these models the alignment variable was either statistically insignificant, had the incorrect sign, or both. Therefore, these findings are not displayed in the paper.

Table 6.3 displays the results from an OLS regression and a fractional probit regression using the new competitive grant funding variable. Column one displays the results from the OLS regression and column two displays the fractional probit model. When only looking at the five agencies which are susceptible to presidential influence the alignment variable becomes positive and statically significant. The results from the OLS regression suggest that a congressional district that is aligned with the president will receive $0.0414 \%$ more annual competitive grant funding than a district that is not aligned with the president, ceteris paribus. Assuming an average annual budget of $1,997,368,206 \$$ for all five agencies this amounts to a $828,708.10 \$$ increase in competitive federal grant funding. However, since the portion of grant funding variable is fractional OLS missspecifies the functional form. The results from the fractional probit regression suggest that, holding all other variables at their mean values, a congressional district that is aligned with the President will receive $0.0393 \%$ more annual competitive grant funding than a district that is not aligned with the President. Assuming the same budget of $1,997,368,206 \$$, this amounts to a $785,764.70 \$$ increase in federal spending.

Table 6.4 examines if the relationship between alignment and competitive grant 
Table 6.2: Individual Agencies Sign Chart

\begin{tabular}{|c|c|c|}
\hline \multicolumn{3}{|c|}{ Independent variable: Alignment } \\
\hline Agency & Sign & P-value \\
\hline $\mathrm{ARC}$ & - & 0.485 \\
\hline $\mathrm{CNCS}^{*}$ & + & 0.014 \\
\hline USDA & + & 0.822 \\
\hline $\mathrm{DOC}^{*}$ & + & 0.015 \\
\hline DOD & - & 0.141 \\
\hline ED & - & 0.700 \\
\hline DOE & - & 0.731 \\
\hline HHS & - & 0.969 \\
\hline HUD $^{* *}$ & + & 0.009 \\
\hline DOJ & - & 0.254 \\
\hline DOL & - & 0.539 \\
\hline NEA & - & 0.819 \\
\hline NEH & - & 0.933 \\
\hline $\mathrm{NSF}^{*}$ & + & 0.032 \\
\hline SBA & + & 0.365 \\
\hline FMCS & - & 0.317 \\
\hline NARA & + & 0.306 \\
\hline USAID & + & 0.596 \\
\hline USACE & - & 0.217 \\
\hline DOS* & + & 0.042 \\
\hline NRC & + & 0.317 \\
\hline SSA & - & 0.591 \\
\hline TREAS & - & 0.701 \\
\hline DHS & - & 0.856 \\
\hline $\mathrm{EAC}$ & + & 0.198 \\
\hline VA & - & 0.298 \\
\hline STB & - & 0.456 \\
\hline DENALI & - & 0.432 \\
\hline DRA* $^{*}$ & - & 0.014 \\
\hline EOP & + & 0.990 \\
\hline GCERC & - & 0.071 \\
\hline
\end{tabular}

funding changes in election years. Research has found that the president engages in distributive politics during years that he is seeking re-election by allocating more funds to swing states, and his constituency (Larcinese et al., 2006; Kriner and Reevies, 2015; and Kang, 2018). Therefore, the President may also allocate more competitive grant funds to congressional districts and states that are represented by partisan aligned members of the H.O.R. and Senate. 
Table 6.3: Alignment and Filtered Competitive Grant Funding

\begin{tabular}{lcc}
\hline \hline & OLS & Fractional Probit \\
\hline Alignment & $0.0004149^{* *}$ & $0.0586704^{* *}$ \\
H.O.R. Majority Party & $(0.0001505)$ & $(0.0169196)$ \\
& 0.0001996 & 0.0360798 \\
H.O.R. Committee Chair & $(0.0002328)$ & $(0.0250621)$ \\
& 0.0008312 & 0.0908864 \\
H.O.R. Ranking Member & $(0.0007975)$ & $(0.0686561)$ \\
H.O.R. Party Leader & 0.0000553 & 0.0138852 \\
H.O.R. Appropriations & $(0.0002474)$ & $(0.0411897)$ \\
H.O.R. Ways and Means & 0.000397 & 0.0745609 \\
& $(0.00073)$ & $(0.1205278)$ \\
H.O.R. Republican & -0.0001108 & -0.0082725 \\
H.O.R. First Term & $(0.0002468)$ & $(0.03271)$ \\
H.O.R. Representative V.S. & -0.0004768 & -0.055211 \\
President V.S. & $(0.0002989)$ & $(0.0375057)$ \\
Senate Alignment & -0.0001067 & $-0.0192298^{*}$ \\
Senator V.S. & $(0.0000628)$ & $(0.0098125)$ \\
Two M.P. Senators & 0.000343 & 0.1494977 \\
Senate Democrat & $(0.000905)$ & $(0.0957366)$ \\
Senate Party Leader & 0.0013973 & 0.1839653 \\
Senate Appropriations & $(0.0007208)$ & $(0.0977134)$ \\
Socio-Economic Controls & -0.0002196 & -0.1651252 \\
District FE & $(0.0023018)$ & $(0.2747452)$ \\
Year FE & $0.0004367^{*}$ & $0.0544818^{*}$ \\
Constant & $(0.0002008)$ & $(0.0243905)$ \\
& $0.0006186^{*}$ & $0.0960391^{* *}$ \\
adj. $R^{2}$ & $(0.0002594)$ & $(0.0329626)$ \\
\hline Stand & -0.0000814 & -0.0113231 \\
& $(0.000147)$ & $(0.018759)$ \\
& -0.0004567 & -0.0405544 \\
& $(0.0004946)$ & $(0.0484022)$ \\
& -0.0004405 & -0.0400465 \\
& $(0.0005659)$ & $(0.0634896)$ \\
& 0.0000881 & 0.0219296 \\
& $(0.0002108)$ & $(0.027749)$ \\
& Yes & Yes \\
& Yes & Yes \\
& -0.0003429 & $-3.050553 * * *$ \\
& $(0.0024541)$ & $(0.262416)$ \\
\hline
\end{tabular}

Standard errors in parentheses clustered by congressional district.

${ }^{*} p<0.05,{ }^{* *} p<0.01,{ }^{* * *} p<0.001$ 
Table 6.4 does not provide any support for this theory. Column one of table 6.4 displays the results of a fractional probit regression using only years where there was a congressional election. In this model neither the district or state alignment variable are statically significant at any conventional level. The district alignment variable has an associated p-value of 0.118 , while the state alignment variable has a p-value of 0.074 . Column two of table 6.4 displays the result from a fractional probit model that examines years in the sample when a presidential election was held. The results are consistent with the congressional elections model. Neither the district nor state alignment variables are statistically significant at any level. The district alignment variable has a p-value of 0.220 , and the state alignment variable has a p-value of 0.479 . These results suggest that aligned districts do not receive a larger share of annual competitive grant funding during elections years.

It is also possible that alignment in the H.O.R. interacts with alignment in the Senate. The president may want to distribute more funds to aligned districts located in aligned states as a way of helping his legislative allies in both the H.O.R. and Senate. Furthermore, the president has very little incentive to allocate more funds to districts represented by dis-aligned members of the H.O.R. in dis-aligned states because he would not be proving support to any members of his own party. Table 6.5 tests the interaction between district and state alignment.

In table 6.5, column one displays the results from an OLS regression and column two displays the results from a fractional probit regression. The findings are largely consistent between both models. The direct effects of district and state alignment are not statically significant, while the interaction term is significant at the 0.05 level. However, since district alignment and state alignment were interacted it makes little sense to examine their individual significance levels. Results from $\mathrm{f}$-tests on all three variables, for both regression in table 6.5, suggest that at least one of the variables is statically significant. The p-values of the f-tests for the OLS regression and the fractional probit regression are 0.000. Since the finding between the OLS regression and the fractional probit regression are largely 
Table 6.4: Election Years

\begin{tabular}{lcc}
\hline \hline & Congressional & Presidential \\
\hline Alignment & 0.0380067 & 0.0424407 \\
& $(0.0243428)$ & $(0.0346156)$ \\
H.O.R. Majority Party & 0.0516828 & 0.0485209 \\
& $(0.0309789)$ & $(0.0373024)$ \\
H.O.R. Committee Chair & 0.0531175 & $0.1718268^{*}$ \\
H.O.R. Ranking Member & $(0.0537598)$ & $(0.0862)$ \\
H.O.R. Party Leader & -0.0320557 & -0.0130801 \\
H.O.R. Appropriations & $(0.053263)$ & $(0.0782881)$ \\
H.O.R. Ways and Means & -0.0178672 & 0.0247118 \\
H.O.R. Republican & $(0.1079583)$ & $(0.226119)$ \\
H.O.R. First Term & -0.0135517 & 0.0433531 \\
H.O.R. Representative V.S. & $(0.0363767)$ & $(0.0461626)$ \\
President V.S. & -0.0653453 & -0.0617524 \\
Senate Aligned & $(0.0393919)$ & $(0.050222)$ \\
Senator V.S. & -0.0160636 & 0.0083977 \\
Two M.P. Senators & $(0.0135608)$ & $(0.0141834)$ \\
Senate Democrat & -0.1865829 & 0.5017737 \\
Senate Party Leader & $(0.099851)$ & $(0.3189348)$ \\
Senate Appropriations & $0.2788057^{*}$ & 0.0329636 \\
Socio-Economic Controls & $(0.1239256)$ & $(0.2159341)$ \\
District FE & -0.0023447 & -0.0423697 \\
Constant & $(0.332382)$ & $(0.6600428)$ \\
& 0.0629183 & 0.0372685 \\
& $(0.0352565)$ & $(0.0526642)$ \\
\hline \hline Star FE & $0.1013662^{* *}$ & -0.0110665 \\
& $(0.0329345)$ & $(0.0509103)$ \\
& -0.0163985 & 0.0082301 \\
& $(0.0289484)$ & $(0.0493403)$ \\
& -0.025508 & -0.0363253 \\
& $(0.0610018)$ & $(0.0657137)$ \\
& -0.048544 & -0.086857 \\
& $(0.0883598)$ & $(0.0764383)$ \\
& 0.0268413 & $0.0945623^{*}$ \\
& $(0.0357807)$ & $(0.0388399)$ \\
& Yes & Yes \\
& $(0.38647222)$ & $(0.8477323)$ \\
\hline
\end{tabular}

Standard errors in parentheses clustered by congressional district.

${ }^{*} p<0.05,{ }^{* *} p<0.01,{ }^{* * *} p<0.001$ 
the same, and the fractional probit model is more robust, only the results from the fraction probit model will be discussed. The results suggest that, holding all other variables at the means, aligned districts in dis-aligned states experience a $0.00636 \%$ decrease in annual competitive grant funding. Holding all other variables at their mean values, dis-aligned districts in aligned states experience a $0.00571 \%$ increase in annual competitive grant funding. Lastly, aligned districts in aligned states receive a $0.06941 \%$ increase in annual competitive grant funding, holding all other variables at their mean values. The findings with regard to aligned districts in aligned states are the only results that have reasonable interpretations. It makes little sense for aligned districts in dis-aligned states to fair worse off than dis-aligned districts in dis-aligned states. Furthermore, the findings suggests that the effect of district and state alignment is quite large. Assuming an average annual budget the results suggest that a district, with all other factors held at their mean values, can experience a 1,386,373\$ increase in competitive grant funding from being aligned with the president and located in aligned states.

The results in this section find very weak evidence for the relationship between alignment with the president and annual competitive grant funding. When looking at all agencies in the sample there is no evidence of a relationship, however this finding may be the results of heterogeneous agency attributes that have not been controlled for. After the portion of annual competitive grant funding variable has been filtered to only include agencies with a significant positive association between district alignment and competitive grant funding the results slightly improve. When examining all years in the sample there is evidence of a significant positive relationship between alignment at the district level and competitive grant funding. However, this relationship is highly sensitive to model specification and the years examined in the analysis. When looking at congressional or presidential election years the significance disappears. Furthermore, when an interaction is added to the model it gives unreasonable results for the direct relationship between district alignment and competitive grant funding. 
Table 6.5: Interaction Between State and District Alignment

\begin{tabular}{|c|c|c|}
\hline & OLS & Fractional Probit \\
\hline \multirow[t]{2}{*}{ Alignment } & -0.0000461 & -0.0107685 \\
\hline & $(0.0002764)$ & $(0.0375056)$ \\
\hline \multirow[t]{2}{*}{ Senate Alignment } & 0.0001133 & 0.009403 \\
\hline & $(0.000258)$ & $(0.0339022)$ \\
\hline \multirow[t]{2}{*}{ Alignment X Senate Alignment } & $0.0007021^{*}$ & $0.1022192^{*}$ \\
\hline & $(0.0003138)$ & $(0.0447574)$ \\
\hline \multirow[t]{2}{*}{ H.O.R. Majority Party } & 0.0002106 & 0.0375424 \\
\hline & $(0.0002337)$ & $(0.0250936)$ \\
\hline \multirow[t]{2}{*}{ H.O.R. Committee Chair } & 0.0008537 & 0.0904222 \\
\hline & $(0.0007974)$ & $(0.0672286)$ \\
\hline \multirow[t]{2}{*}{ H.O.R. Ranking Member } & 0.0000542 & 0.0107185 \\
\hline & $(0.0002466)$ & $(0.0412846)$ \\
\hline \multirow[t]{2}{*}{ H.O.R. Party Leader } & 0.0004306 & 0.0720834 \\
\hline & $(0.0007133)$ & $(0.116837)$ \\
\hline \multirow[t]{2}{*}{ H.O.R. Appropriations } & -0.000104 & -0.0053129 \\
\hline & $(0.0002444)$ & $(0.0317626)$ \\
\hline \multirow[t]{2}{*}{ H.O.R. Ways and Means } & -0.000486 & -0.0568168 \\
\hline & $(0.0002995)$ & $(0.0373591)$ \\
\hline \multirow[t]{2}{*}{ H.O.R. Republican } & -0.0000933 & -0.0182855 \\
\hline & $(0.0000611)$ & $(0.0096842)$ \\
\hline \multirow[t]{2}{*}{ H.O.R. First Term } & 0.0002285 & $0.1395575^{*}$ \\
\hline & $(0.0009196)$ & $(0.0933538)$ \\
\hline \multirow[t]{2}{*}{ H.O.R. Representative V.S. } & 0.0013884 & 0.1811591 \\
\hline & $(0.0007199)$ & $(0.0979565)$ \\
\hline \multirow[t]{2}{*}{ President V.S. } & -0.0002924 & -0.1793253 \\
\hline & $(0.0022991)$ & $(0.2738342)$ \\
\hline \multirow[t]{2}{*}{ Senator V.S. } & $0.0005986^{*}$ & $0.0949745^{* *}$ \\
\hline & $(0.0002582)$ & $(0.0332525)$ \\
\hline \multirow[t]{2}{*}{ Two M.P. Senators } & -0.0000897 & -0.0138633 \\
\hline & $(0.0001469)$ & $(0.0186303)$ \\
\hline \multirow[t]{2}{*}{ Senate Democrat } & -0.0004066 & -0.0371475 \\
\hline & $(0.0004926)$ & $(0.0480842)$ \\
\hline \multirow[t]{2}{*}{ Senate Party Leader } & -0.0004185 & -0.0394033 \\
\hline & $(0.000569)$ & $(0.0640429)$ \\
\hline \multirow[t]{2}{*}{ Senate Appropriations } & 0.0000819 & 0.0207832 \\
\hline & $(0.0002099)$ & $(0.0275027)$ \\
\hline Socio-Economic Controls & Yes & Yes \\
\hline District FE & Yes & Yes \\
\hline Year FE & Yes & Yes \\
\hline \multirow[t]{2}{*}{ Constant } & -0.000734 & $-3.005194^{* * *}$ \\
\hline & $(0.00228)$ & $(0.2604196)$ \\
\hline$N$ & 7394 & 7394 \\
\hline adj. $R^{2}$ & 0.0037 & \\
\hline
\end{tabular}

Standard errors in parentheses clustered by congressional district.

${ }^{*} p<0.05,{ }^{* *} p<0.01,{ }^{* * *} p<0.001$ 
There are two possible explanations for these findings. First, it may be that only aligned districts in aligned states experience an increase in competitive grant funding, while district alignment in a dis-aligned state has no effect on annual competitive grant funding. There is some evidence of this relationship from the findings in table 6.5. In both models in table 6.5 the interaction term was positive and statically significant at the 0.05 level, while both the direct effect of state alignment and district alignment were not statically significant at any level.

Second, the year 2011 may mark a structural break in the federal spending time series. In 2011 the congressional moratorium on earmarks was implemented which may have substantially reduced the level of influence that members of Congress had over federal spending (White, 2018). The proceeding sections will examine the relationship between partisan alignment with the president and competitive grant funding in the earmark era and post earmark era to determine if this relationship has changed after the moratorium was enacted. In order to examine how the enactment of the earmark moratorium may have altered the relationship between alignment and annual competitive grant funding the sample was divided into two parts. An "earmark era" time period which contains observations from 2001 to 2010, and a "post earmark" time period that contains observation from 2012 to 2017.

\subsection{Earmark Era}

The results for the base model estimates in the earmark era are displayed in table 6.6. Column one of table 6.6 displays the results of an OLS regression and column two of table 6.6 displays the results from a fractional probit regression. The first term variable was omitted from the OLS regressions estimated in this section because of perfect multicollinearity. Neither of these models provide any support for a relationship between district or state alignment and annual competitive grant funding in the earmark era. The district alignment variable is not statistically 
significant at any level and has the incorrect sign. Although, the state alignment variable has the correct sign it is also statistically insignificant in both models of table 6.6. The state alignment variable has a p-value of 0.070 for the fractional probit regression.

In order to examine the role of elections in the earmark era the congressional and presidential elections models were re-estimated using only observation prior to 2011. The results are displayed in table 6.7. Column one displays a fractional probit model only using observation from years when a congressional election was held in the earmark era, and column two displays a fractional probit model using only observations from years with a presidential election in the earmark era. The finding are consistent with the results in the previous section. Both district alignment and state alignment are not statistically significant in the congressional election model at convectional levels. The district alignment variable has a p-value of 0.302 , and the state alignment variable has a p-value of 0.102 . With regard to presidential elections the district and state alignment variables are not statistically significant either. In the presidential election model the p-value associated with district alignment is 0.521 and the p-value associated with state alignment is 0.666. Furthermore, the district alignment variable has the incorrect sign.

Lastly, the interaction model was re-estimated for the earmark era. The results are displayed in table 6.8. Column one displays the findings from an OLS regression and column two displays the findings from a fractional probit model. The finding are largely consistent between the two models. Therefore only the results from the fractional probit model will be discussed. The district alignment, state alignment, and interaction term are all statistically insignificant in the fractional probit model. Consistent with the result in the previous section the estimated direct effect of district alignment is negative. In order to test the joint significance of all three coefficients an f-test was conducted and the results indicate that none of the coefficient are significantly different from zero. The p-value associated with the f-test is 0.1867 . Thus, the interaction between district alignment and state 
Table 6.6: Earmark Era

\begin{tabular}{lcc}
\hline \hline & OLS & Fractional Probit \\
\hline Alignment & -0.0001169 & -0.0154595 \\
& $(0.0001633)$ & $(0.0229089)$ \\
H.O.R. Majority Party & $0.0007619^{* *}$ & $0.1145645^{* * *}$ \\
& $(0.0002589)$ & $(0.0319676)$ \\
H.O.R. Committee Chair & 0.000607 & 0.0642617 \\
& $(0.0008871)$ & $(0.0739261)$ \\
H.O.R. Ranking Member & -0.0002234 & 0.0013112 \\
H.O.R. Party Leader & $(0.000573)$ & $(0.0698341)$ \\
H.O.R. Appropriations & 0.000000 & 0.0287755 \\
& $(0.0006014)$ & $(0.1075876)$ \\
H.O.R. Ways and Means & -0.0002655 & -0.0350302 \\
& $(0.0002928)$ & $(0.0423202)$ \\
H.O.R. Republican & -0.000601 & -0.0645317 \\
H.O.R. First Term & $(0.0003807)$ & $(0.0475565)$ \\
H.O.R. Representative V.S. & -0.0001167 & -0.0155242 \\
President V.S. & $(0.0000982)$ & $(0.0149258)$ \\
Senate Alignment & & -0.1071126 \\
& & $(0.2188683)$ \\
Senator V.S. & $0.0022575^{* *}$ & $0.2770206^{* *}$ \\
Two M.P. Senators & $(0.0008139)$ & $(0.0966257)$ \\
Senate Democrat & -0.001434 & -0.2947947 \\
Senate Party Leader & $(0.0029208)$ & $(0.3985455)$ \\
Senate Appropriations & 0.0004602 & 0.0571806 \\
Socio-Economic Controls & $(0.0002362)$ & $(0.031532)$ \\
District FE & $0.0011135^{* *}$ & $0.1683123^{* * *}$ \\
Year FE & $(0.0003747)$ & $(.0446436)$ \\
Constant & -0.0001029 & -0.0215704 \\
adj. $R^{2}$ & $(0.0001734)$ & $(0.0258144)$ \\
\hline \hline Stana & -0.0001602 & 0.0080117 \\
& $(0.0005017)$ & $(0.0570494)$ \\
& -0.0001015 & 0.0101205 \\
& $(0.0006736)$ & $(0.070852)$ \\
& -0.0002336 & -0.0203054 \\
& $(0.0005448)$ & $(0.0690233)$ \\
& Yes & Yes \\
& Yes & Yes \\
& -0.006443 & $-3.391871^{* * *}$ \\
& $(0.006407)$ & $(0.535602)$ \\
\hline
\end{tabular}

Standard errors in parentheses clustered by congressional district.

${ }^{*} p<0.05,{ }^{* *} p<0.01,{ }^{* * *} p<0.001$ 
Table 6.7: Earmark Era: Elections

\begin{tabular}{lcc}
\hline \hline & Congressional & Presidential \\
\hline Alignment & 0.0672003 & 0.0754658 \\
& $(0.0651118)$ & $(0.1174822)$ \\
H.O.R. Majority Party & 0.0431271 & 0.0510357 \\
& $(0.0630094)$ & $(0.1215556)$ \\
H.O.R. Committee Chair & -0.025233 & $0.3702871^{* *}$ \\
& $(0.068213)$ & $(0.1363483)$ \\
H.O.R. Ranking Member & -0.025908 & 0.1803592 \\
& $(0.0783675)$ & $(0.1385375)$ \\
H.O.R. Party Leader & -0.0852258 & 0.0733305 \\
& $(0.096228)$ & $(0.1378492)$ \\
H.O.R. Appropriations & -0.028472 & 0.053697 \\
& $(0.0484678)$ & $(0.0779664)$ \\
H.O.R. Ways and Means & -0.0605511 & -0.0292659 \\
H.O.R. republican & $(0.0545539)$ & $(0.1468406)$ \\
H.O.R. First Term & -0.029683 & 0.0175436 \\
H.O.R. Representative V.S. & $(0.0185152)$ & $(0.0320836)$ \\
President V.S. & 0.0818679 & -3.063001 \\
Senate Alignment & $(0.2932768)$ & $(1.776167)$ \\
Senator Vote Share & 0.275157 & -0.0628428 \\
Two M.P. Senators & $(0.1149353)$ & $(0.2668064)$ \\
Senate Democrat & -0.2865125 & $-2.440645 *$ \\
Senate Party Leader & $(0.4750669)$ & $(1.075107)$ \\
Senate Appropriations & 0.0703905 & 0.0455669 \\
Socio-Economic Controls & $(0.0430043)$ & $(0.1056261)$ \\
District FE & $0.1730699^{* *}$ & -0.02092 \\
Constant & $(0.0447712)$ & $(0.0876555)$ \\
& -0.0091454 & 0.1195241 \\
& $(0.0343674)$ & $(0.1199237)$ \\
& 0.018481 & 0.1705367 \\
Ytar FE & $(0.0690678)$ & $(0.1290713)$ \\
& 0.0064985 & -0.0263496 \\
& $(0.0905699)$ & $(0.0918655)$ \\
& 0.0084839 & $0.2115453^{*}$ \\
& $(0.0877345)$ & $(0.0884643)$ \\
& Yes & Yes \\
& $(0.8796027)$ & $(2.047956)$ \\
\hline
\end{tabular}

Standard errors in parentheses clustered by congressional district.

${ }^{*} p<0.05,{ }^{* *} p<0.01,{ }^{* * *} p<0.001$ 
alignment does not appear to have an effect on competitive grant funding in the earmark era.

The results presented in this section find no evidence of a relationship between alignment and competitive grant funding in the earmark era. When examining all years prior to 2011 neither the district alignment nor the state alignment variables were statistically significant. The relationship remained insignificant for congressional and presidential election years. Furthermore, the direction of the relationship between district alignment and competitive grant funding was negative in presidential election years. Lastly, the interaction between state and district alignment was also insignificant in the earmark era.

These findings may in part be explained by the fact that during the earmark era congress had considerably more power over federal spending than the president. Bogie (2018) notes that prior to the earmark moratorium earmarks allowed federal spending to heavily favor powerful members of Congress. Kuhn (2017) notes that the congressional moratorium on earmarks has weakened congressional channels of influence over distributive spending, while leaving presidential influence unaffected. Therefore, during the earmark era majority party status, congressional electoral politics, and committee membership may have been the relevant factors influencing competitive grant funding, not alignment with the president. This is consistent with the current findings. Although the coefficients associated with the political control variables do not have causal interpretations, majority party status in the H.O.R. and Representative vote share were statistically significant and positively related to competitive grant funding in four of the six models estimated in this section providing more support for the notion that political factors in the H.O.R. influenced the distribution of competitive grant funding, not presidential influence. 
Table 6.8: Earmark Era: Interaction between State and District Alignment

\begin{tabular}{|c|c|c|}
\hline & OLS & Fractional Probit \\
\hline Alignment & $\begin{array}{l}-0.0004715 \\
(0.0002968)\end{array}$ & $\begin{array}{c}-0.057462 \\
(0.042296)\end{array}$ \\
\hline Senate Alignment & $\begin{array}{l}0.0001804 \\
(0.000331)\end{array}$ & $\begin{array}{c}0.0256982 \\
(0.0464094)\end{array}$ \\
\hline Alignment X Senate Aliment & $\begin{array}{c}0.0005458 \\
(0.0003901)\end{array}$ & $\begin{array}{c}0.0634851 \\
(0.0562535)\end{array}$ \\
\hline H.O.R. Majority Party & $\begin{array}{l}0.0007652^{* *} \\
(0.0002585)\end{array}$ & $\begin{array}{l}0.1141241^{* *} \\
(0.0319208)\end{array}$ \\
\hline H.O.R. Committee Chair & $\begin{array}{c}0.0006355 \\
(0.0008874)\end{array}$ & $\begin{array}{c}0.0646809 \\
(0.0725054)\end{array}$ \\
\hline H.O.R. Ranking Member & $\begin{array}{l}-0.0002373 \\
(0.0005756)\end{array}$ & $\begin{array}{l}-0.0028525 \\
(0.0710874)\end{array}$ \\
\hline H.O.R. Party Leader & $\begin{array}{c}0.0000288 \\
(0.0006057)\end{array}$ & $\begin{array}{c}0.0260622 \\
(0.1065165)\end{array}$ \\
\hline H.O.R. Appropriations & $\begin{array}{c}-0.0002511 \\
(0.000292)\end{array}$ & $\begin{array}{c}-0.0327054 \\
(0.0421046)\end{array}$ \\
\hline H.O.R. Ways and Means & $\begin{array}{c}-0.0006052 \\
(0.0003819)\end{array}$ & $\begin{array}{c}-0.0652946 \\
(0.0474702)\end{array}$ \\
\hline H.O.R. Republican & $\begin{array}{c}-0.0001099 \\
(0.0000978)\end{array}$ & $\begin{array}{l}-0.0159175 \\
(0.0149893)\end{array}$ \\
\hline H.O.R. First Term & & $\begin{array}{c}-0.1145448 \\
(0.2193596)\end{array}$ \\
\hline H.O.R. Representative V.S. & $\begin{array}{l}0.0022539^{* *} \\
(0.0008136)\end{array}$ & $\begin{array}{c}0.2760058^{*} \\
(0.096889)\end{array}$ \\
\hline President V.S. & $\begin{array}{l}-0.0015134 \\
(0.0029049)\end{array}$ & $\begin{array}{c}-0.300392 \\
(0.3954576)\end{array}$ \\
\hline Senator V.S. & $\begin{array}{l}0.0010987^{* *} \\
(0.0003714)\end{array}$ & $\begin{array}{l}0.1659717^{* *} \\
(0.0444551)\end{array}$ \\
\hline Two M.P. Senators & $\begin{array}{l}-0.0001038 \\
(0.0001731)\end{array}$ & $\begin{array}{l}-0.0224197 \\
(0.0255996)\end{array}$ \\
\hline Senator Democrat & $\begin{array}{l}-0.0001435 \\
(0.0005011)\end{array}$ & $\begin{array}{c}-0.0092571 \\
(0.0565486)\end{array}$ \\
\hline Senate Party Leader & $\begin{array}{l}-0.000099 \\
(0.0006776)\end{array}$ & $\begin{array}{c}0.0101204 \\
(0.0713022)\end{array}$ \\
\hline Senate Appropriations & $\begin{array}{l}-0.0002267 \\
(0.0005413)\end{array}$ & $\begin{array}{c}-0.0189852 \\
(0.0684736)\end{array}$ \\
\hline Socio-Economic Controls & Yes & Yes \\
\hline District FE & Yes & Yes \\
\hline Year FE & Yes & Yes \\
\hline Constant & $\begin{array}{l}-0.0048987 \\
(0.0057668)\end{array}$ & $\begin{array}{c}-3.161932^{* * *} \\
(0.483623)\end{array}$ \\
\hline $\begin{array}{l}N \\
\text { adj. } R^{2}\end{array}$ & $\begin{array}{c}4350 \\
0.0095\end{array}$ & 4350 \\
\hline
\end{tabular}

Standard errors in parentheses clustered by congressional district.

${ }^{*} p<0.05,{ }^{* *} p<0.01,{ }^{* * *} p<0.001$ 


\subsection{Post Earmark Era}

Table 6.9 displays the results for the base model in the post earmark era. Column one displays the findings from an OLS regression and column two displays the findings from a fractional probit regression. Once again the alignment variables remains statistically insignificant. The p-value associated with the district alignment variable is 0.342 in the OLS regression and 0.506 in the fractional probit regression. With regard to state alignment it has a significant effect on competitive grant funding in both models. The p-value associated with the state alignment variable is 0.030 in the OLS regression, and 0.110 in the fractional probit regression. The findings from the fractional probit model suggest that, holding all other variable at their mean values, a congressional district located in an aligned state will experience a $0.05783 \%$ increase in annual competitive grant funding. Assuming an average budget of $1,416,366,566 \$$ in the post earmark era, this is a $819,084.79 \$$ increase in annual competitive grant funding.

When examining election years the results are largely consistent with the findings from the past two sections. Table 6.10 displays the results from the two elections models. Column one presents the results from a fractional probit regression using only observation from years when a congressional election was held in the post earmark era, and column two displays the results from a fractional probit model using only observation of years when a presidential election was held in the post earmark era. Once again the district and state alignment variables remain statistically insignificant for the congressional elections model at all levels. In the congressional elections model the district alignment variable has a p-value of 0.262 and the state alignment variable has a p-value of 0.924. Furthermore, the state alignment variable has the incorrect sign associated with it. With regard to presidential elections the district and state alignment variables remains statistically insignificant at all levels. The district alignment variable has a p-value of 0.119 , and the state alignment variable has a p-value of 0.589 . 
Table 6.9: Post Earmark Era

\begin{tabular}{lcc}
\hline \hline & OLS & Fractional Probit \\
\hline Alignment & 0.0002213 & 0.0209424 \\
& $(0.0002327)$ & $(0.0314813)$ \\
H.O.R. Majority Party & 0.0005283 & 0.0776831 \\
& $(0.0004231)$ & $(0.0575097)$ \\
H.O.R. Committee Chair & -0.0002813 & -0.0453709 \\
& $(0.0003886)$ & $(0.0734202)$ \\
H.O.R. Ranking Member & 0.0006667 & $0.1466505^{*}$ \\
H.O.R. Party Leader & $(0.0004012)$ & $(0.0707424)$ \\
H.O.R. Appropriations & $-0.0013365^{*}$ & $-0.2453047^{* * *}$ \\
H.O.R. Ways and Means & $(0.000631)$ & $(0.0457645)$ \\
& -0.0003702 & -0.0542727 \\
H.O.R. Republican & $(0.0003354)$ & $(0.0490102)$ \\
H.O.R. First Term & -0.0000118 & -0.008971 \\
H.O.R. Representative Vote Share & $(0.0006978)$ & $(0.0837345)$ \\
President V.S. & -0.0000878 & -0.0160286 \\
Senate Alignment & $(0.000145)$ & $(0.0221213)$ \\
Senator V.S. & $-0.00133^{*}$ & $-0.2297596^{*}$ \\
Two M.P. Senators & $(0.000565)$ & $(0.0749805)$ \\
Senate Democrat & -0.0011578 & -0.1906905 \\
Senate Party Leader & $(0.0010496)$ & $(0.1683282)$ \\
Senate Appropriations & 0.0012557 & 0.0449938 \\
Socio-Economic Controls & $(0.0021658)$ & $(0.3042608)$ \\
District FE & $0.00074^{*}$ & $0.0934094^{*}$ \\
Year FE & $(0.0003278)$ & $(0.0431332)$ \\
Constant & -0.0005368 & -0.0584146 \\
adj. $R^{2}$ & $(0.000337)$ & $(0.0459263)$ \\
\hline Stans & -0.0001542 & -0.0213026 \\
& $(0.0002073)$ & $(0.0274913)$ \\
& -0.0009841 & -0.1196697 \\
& $(0.0007079)$ & $(0.0862925)$ \\
& -0.0014452 & -0.2073688 \\
& $(0.0009902)$ & $(0.134953)$ \\
& 0.0004102 & $0.0743035^{*}$ \\
& $(0.0002292)$ & $(0.0367691)$ \\
& Yes & Yes \\
& Yes & Yes \\
& 0.0317016 & 1.250094 \\
& $(0.0165097)$ & $(2.399833)$ \\
\hline
\end{tabular}

Standard errors in parentheses clustered by congressional district.

${ }^{*} p<0.05,{ }^{* *} p<0.01,{ }^{* * *} p<0.001$ 
Table 6.10: Post Earmark Era: Elections

\begin{tabular}{|c|c|c|}
\hline & Congressional & Presidential \\
\hline Alignment & $\begin{array}{c}0.0361454 \\
(0.0322316)\end{array}$ & $\begin{array}{c}0.077038 \\
(0.0493717)\end{array}$ \\
\hline H.O.R. Majority Party & $\begin{array}{c}0.112908 \\
(0.0646799)\end{array}$ & $\begin{array}{c}0.0043153 \\
(0.0727831)\end{array}$ \\
\hline H.O.R. Committee Chair & $\begin{array}{c}0.010449 \\
(0.0884044)\end{array}$ & $\begin{array}{c}0.0166431 \\
(0.1135895)\end{array}$ \\
\hline H.O.R. Ranking Member & $\begin{array}{c}0.0527671 \\
(0.0801475)\end{array}$ & $\begin{array}{c}0.1421951 \\
(0.1038487)\end{array}$ \\
\hline H.O.R. Party Leader & $\begin{array}{c}-0.2056092^{* *} \\
(0.0603928)\end{array}$ & $\begin{array}{l}-0.1724501 \\
(0.1768547)\end{array}$ \\
\hline H.O.R. Appropriations & $\begin{array}{l}-0.0484488 \\
(0.0606247)\end{array}$ & $\begin{array}{l}-0.0270164 \\
(0.0649896)\end{array}$ \\
\hline H.O.R. Ways and Means & $\begin{array}{l}-0.043955 \\
(0.047694)\end{array}$ & $\begin{array}{c}0.0182768 \\
(0.0498169)\end{array}$ \\
\hline H.O.R. Republican & $\begin{array}{l}-0.0188885 \\
(0.0253872)\end{array}$ & $\begin{array}{c}0.0114022 \\
(0.0309861)\end{array}$ \\
\hline H.O.R. First Term & $\begin{array}{c}-0.5189593^{* * *} \\
(0.1315097)\end{array}$ & $\begin{array}{l}-2.248936^{*} \\
(2.988433)\end{array}$ \\
\hline H.O.R. Representative V.S. & $\begin{array}{c}-0.283929 \\
(0.2293453)\end{array}$ & $\begin{array}{l}-0.4184749 \\
(0.3442471)\end{array}$ \\
\hline President V.S. & $\begin{array}{c}0.1697124 \\
(0.3513014)\end{array}$ & $\begin{array}{l}0.4299787 \\
(0.656483)\end{array}$ \\
\hline Senate Alignment & $\begin{array}{l}-0.0083755 \\
(0.0881917)\end{array}$ & $\begin{array}{c}0.082248 \\
(0.1523461)\end{array}$ \\
\hline Senator V.S. & $\begin{array}{l}-0.0437719 \\
(0.0441375)\end{array}$ & $\begin{array}{l}-0.0092399 \\
(0.0767721)\end{array}$ \\
\hline Two M.P. Senators & $\begin{array}{c}0.0531199 \\
(0.0826754)\end{array}$ & $\begin{array}{l}-0.076019 \\
(0.142226)\end{array}$ \\
\hline Senate Democrat & $\begin{array}{l}-0.0468092 \\
(0.1160059)\end{array}$ & $\begin{array}{c}-0.100874 \\
(0.1725678)\end{array}$ \\
\hline Senate Party Leader & $\begin{array}{l}0.1623837^{* *} \\
(0.6093934)\end{array}$ & $\begin{array}{c}0.166138 \\
(0.8628029)\end{array}$ \\
\hline Senate Appropriations & $\begin{array}{c}0.0622085 \\
(0.0476118)\end{array}$ & $\begin{array}{c}0.0702505 \\
(0.0646154)\end{array}$ \\
\hline Socio-Economic Controls & Yes & Yes \\
\hline District FE & Yes & Yes \\
\hline Year FE & Yes & Yes \\
\hline Constant & $\begin{array}{c}-3.161^{* * *} \\
(0.556) \\
\end{array}$ & $\begin{array}{r}-0.3614794 \\
(2.137849) \\
\end{array}$ \\
\hline$N$ & 1305 & 870 \\
\hline
\end{tabular}

Standard errors in parentheses clustered by congressional district.

${ }^{*} p<0.05,{ }^{* *} p<0.01,{ }^{* * *} p<0.001$ 
Lastly, table 6.11 displays the results from the base model with the inclusion of an interaction between district and state alignment in the post earmark era. Column one displays the results from an OLS regression and column two displays the results from a fractional probit regression. Once again the findings are largely consistent between the two models, therefore only the results from the fractional probit model will be discussed in depth.

The findings in table 6.11 , for the post earmark era, differ from the results presented in the previous section. The effect of district alignment and the interaction term are positive but statically insignificant, while the direct effect of state alignment is positive and statically significant. In order to test the joint significance of all three coefficients an f-test was applied. The results indicate that at least one of the coefficients is statically significant. The f-test results have a p-value of 0.0120. The findings indicate that, holding all other factors at their mean, an aligned district in a dis-aligned state will receive a $0.01086 \%$ increase in annual competitive grant funding. A dis-aligned district in an aligned state will receive a $0.05584 \%$ increase in annual competitive grant funding, holding all other variables at their mean. Lastly, an aligned district in an aligned state will receive a $0.07075 \%$ increase in annual competitive grant funding, holding all other variables at their mean values. This amounts to a $1,002,079.30 \$$ increase in federal funds, assuming an average annual budget in the post earmark era.

The results in this section find that alignment has an effect on competitive grant funding in the post earmark era, given certain conditions. In presidential elections years aligned districts received a larger share of competitive grant funding, while alignment at the state level had no effect on competitive grant funding. Furthermore, the results from the interaction suggest that aligned districts in aligned states receive the largest share of competitive grant funds. Therefore, in the post earmark era presidential alignment has some influence on competitive grant funding. 
Table 6.11: Post Earmark Era: Interaction between State and District Alignment

\begin{tabular}{|c|c|c|}
\hline & OLS & Fractional Probit \\
\hline \multirow[t]{2}{*}{ Alignment } & 0.0003355 & 0.0198997 \\
\hline & $(0.0003809)$ & $(0.0593278)$ \\
\hline \multirow[t]{2}{*}{ Senate Alignment } & $0.0008153^{*}$ & $0.0927677^{*}$ \\
\hline & $(0.0003563)$ & $(0.0466316)$ \\
\hline \multirow[t]{2}{*}{ Alignment X Senate Alignment } & -0.0001725 & 0.0015176 \\
\hline & $(0.0003957)$ & $(0.0668311)$ \\
\hline \multirow[t]{2}{*}{ H.O.R. Majority Party } & 0.0005175 & 0.0777781 \\
\hline & $(0.0004219)$ & $(0.0575298)$ \\
\hline \multirow[t]{2}{*}{ H.O.R. Committee Chair } & -0.0002821 & -0.0453992 \\
\hline & $(0.0003885)$ & $(0.0735478)$ \\
\hline \multirow[t]{2}{*}{ H.O.R. Ranking Member } & 0.0006638 & $0.14665^{*}$ \\
\hline & $(0.0004032)$ & $(0.0707314)$ \\
\hline \multirow[t]{2}{*}{ H.O.R. Party Leader } & $-0.0013469^{*}$ & $-0.245326^{* * *}$ \\
\hline & $(0.0006265)$ & $(0.045768)$ \\
\hline \multirow[t]{2}{*}{ H.O.R. Appropriations } & -0.000373 & -0.0541834 \\
\hline & $(0.0003349)$ & $(0.0490604)$ \\
\hline \multirow[t]{2}{*}{ H.O.R. Ways and Means } & -0.0000005 & -0.0090276 \\
\hline & $(0.0006965)$ & $(0.0833624)$ \\
\hline \multirow[t]{2}{*}{ H.O.R. Republican } & -0.0000866 & -0.0160393 \\
\hline & $(0.0001452)$ & $(0.0221077)$ \\
\hline \multirow[t]{2}{*}{ H.O.R. First Term } & $-0.0012907^{*}$ & $-0.2300951^{* *}$ \\
\hline & $(0.000565)$ & $(0.0758216)$ \\
\hline \multirow[t]{2}{*}{ H.O.R. Representative V.S. } & -0.0011651 & -0.1907843 \\
\hline & $(0.0010495)$ & $(0.1688187)$ \\
\hline \multirow[t]{2}{*}{ President V.S. } & 0.0012288 & 0.0449688 \\
\hline & $(0.0021584)$ & $(0.3044593)$ \\
\hline \multirow[t]{2}{*}{ Senator V.S. } & -0.0005304 & -0.0584158 \\
\hline & $(0.000336)$ & $(0.0459194)$ \\
\hline \multirow[t]{2}{*}{ Two M.P. Senator s } & -0.0001533 & -0.021271 \\
\hline & $(0.0002081)$ & $(0.027317)$ \\
\hline \multirow[t]{2}{*}{ Senate Democrat } & -0.0010124 & -0.1193889 \\
\hline & $(0.0007033)$ & $(0.0857362)$ \\
\hline \multirow[t]{2}{*}{ Senate Party Leader } & -0.0014472 & -0.2074675 \\
\hline & $(0.0009901)$ & $(0.1347517)$ \\
\hline \multirow[t]{2}{*}{ Senate Appropriations } & 0.0004111 & $0.0742832^{*}$ \\
\hline & $(0.0002291)$ & $(0.0367438)$ \\
\hline Socio-Economic Controls & Yes & Yes \\
\hline District FE & Yes & Yes \\
\hline Year FE & Yes & Yes \\
\hline \multirow[t]{2}{*}{ Constant } & 0.0316337 & 1.187371 \\
\hline & $(0.0164641)$ & $(2.32442)$ \\
\hline$N$ & 2609 & 2609 \\
\hline $\operatorname{adj} . R^{2}$ & 0.0019 & \\
\hline
\end{tabular}

Standard errors in parentheses clustered by congressional district.

${ }^{*} p<0.05,{ }^{* *} p<0.01,{ }^{* * *} p<0.001$ 


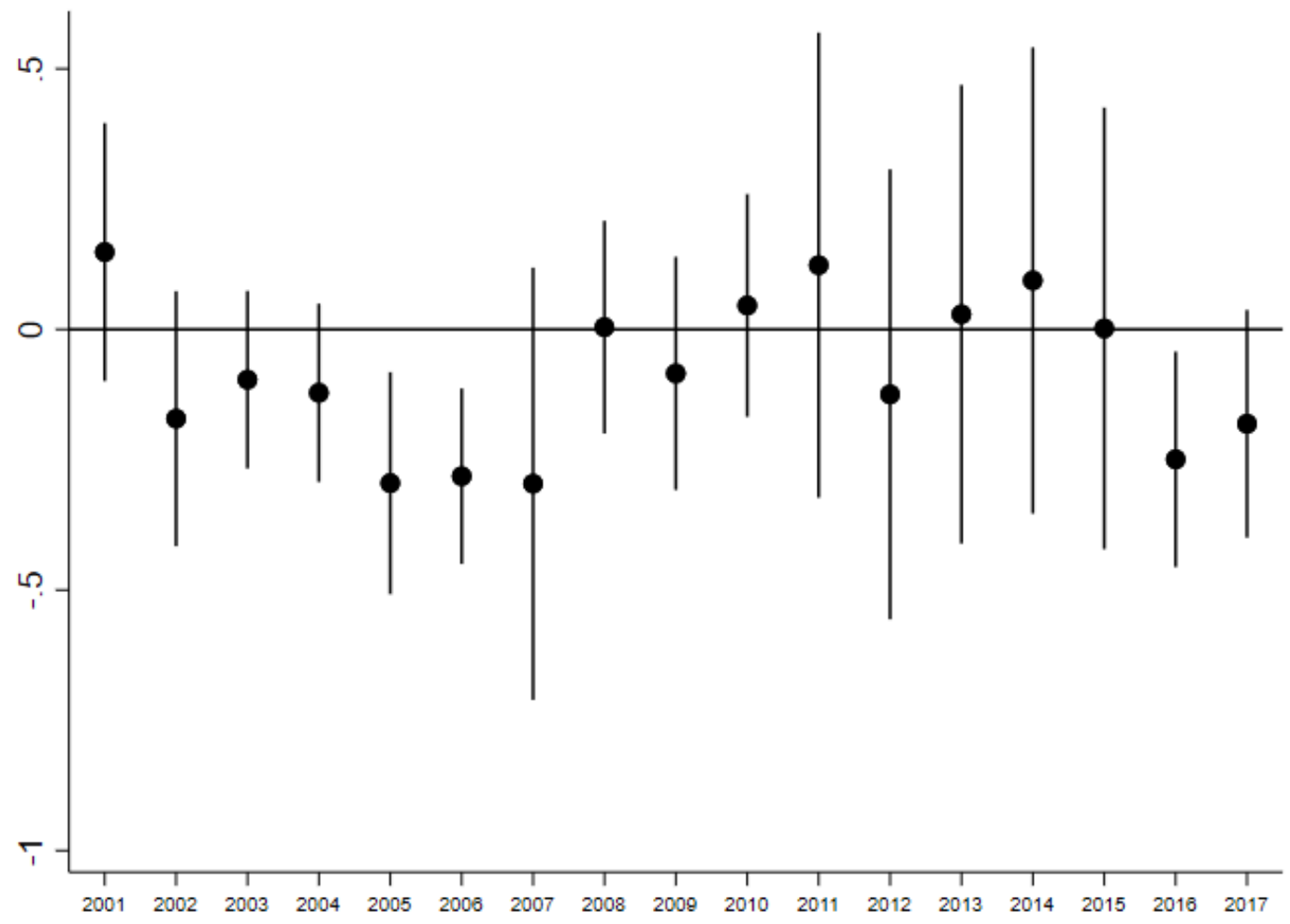

Figure 6.1: Alignment Coefficient Plot

\subsection{Event Study}

This section further investigates how the relationship between alignment and competitive grant funding may change through time by conducting an event study analysis. Figure 6.1 displays the results for the baseline model. These results were obtained by estimating the fractional probit model in table 6.3 with the inclusion of an interaction between the district alignment variable and all of the year dummies. Figure 6.1 plots the point estimates of the coefficients associated with the alignment year interaction terms and the $95 \%$ confidence interval for each coefficient.

The findings in figure 6.1 suggest that the relationship between alignment and the portion of annual competitive grant funding is not conditional on the year. There is not a discernible pattern in the point estimates across time. The point estimates of the coefficient appear to oscillate around zero, however, there is not a clear difference in the trend of the point estimates before and after the enactment 


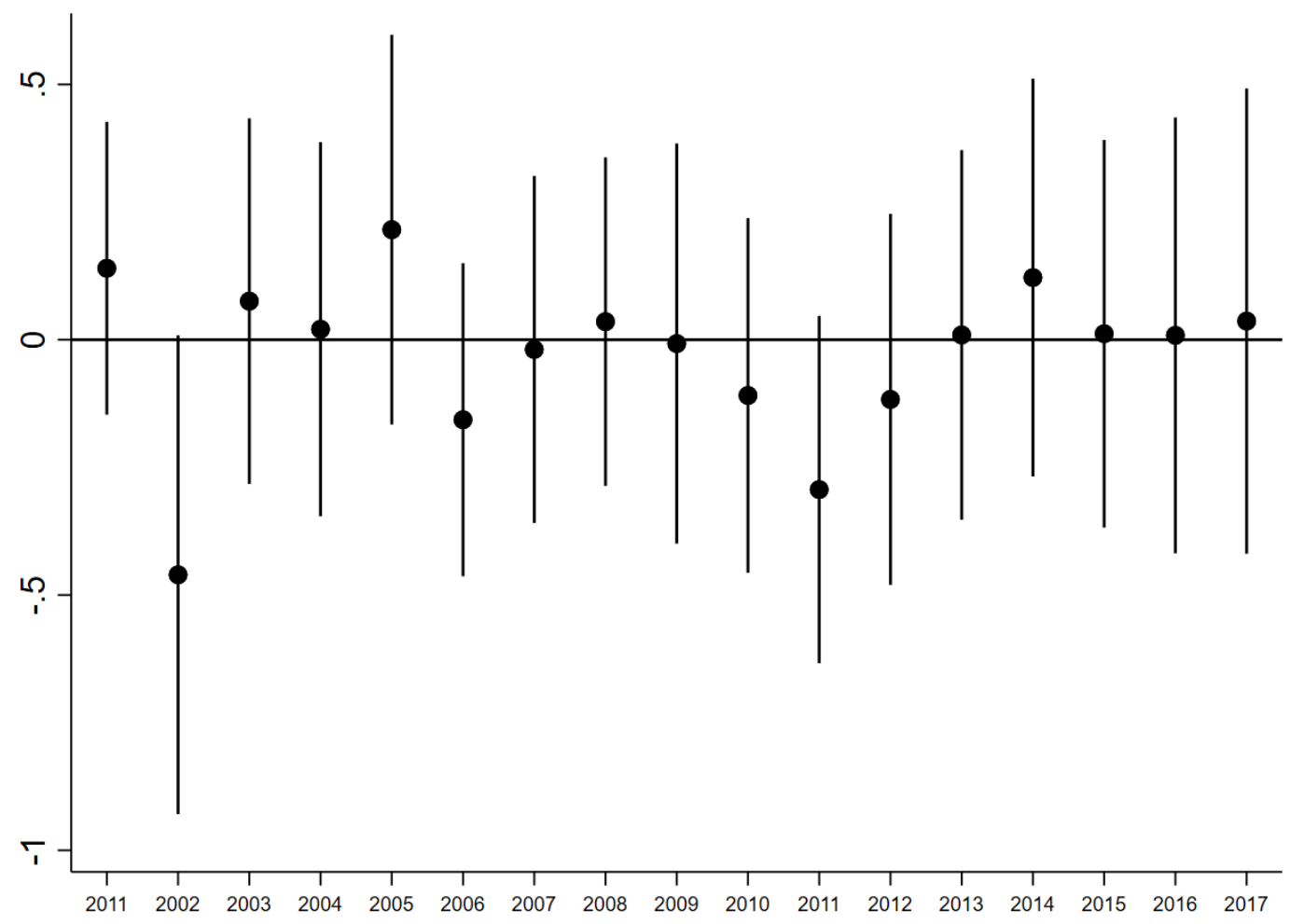

Figure 6.2: Interaction Between District and State Alignment

of the earmark moratorium in 2011. There is also no clear time trend when only looking at the point estimates of coefficients associated with congressional election years or presidential election years.

The findings in 6.1 may be explained by the fact that the model does not account for the interaction between alignment at the district and state levels. Findings from the previous sections suggest that aligned districts located in aligned states received the largest share of competitive grant funding and that this relationship materialized after the enactment of the earmark moratorium. Figure 6.2 examines if the relationship between aligned districts located in aligned states and competitive grant funding is conditioned by the year. The model estimated in figure 6.2 is the baseline fractional probit interaction model estimated in table 6.5 with the inclusion of a full interaction between district alignment, state alignment, and all of the year dummies.

The findings in figure 6.2 provide support for this theory. Although none of the coefficients in figure 6.2 are statically significant there is a discernible trend in the 
point estimates of the effect of district and state alignment. Prior to 2011, in the earmark era, there does not appear to be a relationship between the aligned district located in aligned states and competitive grant funding. The point estimates are random scattered above and below zero, and starting in 2008 the effect of the interaction between district and state alignment on competitive grant funding appears to be growing more negative. This is most likely the result of a series of budget appropriations reforms that congress started enacting in 2007 to curb government spending and corruption (Gordon, 2018; White, 2015). However, after the enactment of the earmark moratorium, in 2011, the magnitude of the yearly effect of the interaction between alignment at the district and state level begins to increase. This suggests that the moratorium on earmarks may have empowered presidential influence in the appropriations process, with the president directing more funds to aligned districts located in aligned states. 


\section{Chapter 7}

\section{Conclusion}

The results from this analysis find weak support for the relationship between partisan alignment with the president and the portion of annual competitive grant funding that a congressional district receives. When examining total competitive intergovernmental grants there does not appear to be any relationship between competitive grant funding and alignment with the president. However, this null finding is the result of agency heterogeneity. Consistent with past research (Bertelli and Grose, 2009; Ting, 2012), results suggest that federal agency respond differently to alignment with the president. Some agencies appear to be susceptible to presidential influence while others are not effected by alignment. When only examining agencies that are susceptible to influence there is a weak positive relationship between alignment and competitive grant funding.

These findings present somewhat of a challenge the results from Berry et al. (2010) which find strong evidence of a relationship between a congressional district's alignment with the president and the amount of federal funds the district receives. However, the model utilized in this analysis is more robust due to the fact that it controlled for senate variables and socio-economic factors, both of which were omitted from Berry et al.'s model. Furthermore, this analysis examined aggregate agency spending while Berry et al. examined 26 individual programs. There may be a weak relationship between alignment and competitive grant funding at the agency level, however some federal programs, such as T.I.G.E.R., may 
be highly susceptible to presidential influence. Thus there could be a strong relationship at the individual program level.

The results also suggest that the effect of alignment on annual competitive grant funding does not change in election years. This somewhat contradicts finds from Larcinese et al. (2006), Kriner and Reevies (2015), and Kang (2018) who all find that the president has a higher tendency to engage in distributive politics during elections years. However, neither the state nor district alignment variables were significant in any of the election model, and this holds for both the pre and post earmark periods. Furthermore, the results from the event study analysis suggests that aligned districts do not receive an increase in competitive grant funding during election years.

The results from the earmark ban analysis also provides some support for White's (2018) argument that the earmark moratorium empowers the president in the grant appropriations process. Indeed the alignment variables were not statistically significant in any of the models estimated during the earmark era. This finding is attributed to the fact that during the earmark era powerful members of Congress had considerable influence over the distribution of federal funding (Bogie, 2018), not the president. When examining the post earmark period the results suggest that aligned districts located in aligned states tend to receive a higher portion of annual competitive grant funding. In the baseline model findings indicate that the state alignment has a significant effect on the portion of annual competitive grant funding in the post earmark period, while district alignment remains insignificant. However, this model fails to account for the interaction between district and state alignment. The results from the interaction models indicate that aligned districts located in aligned states received the largest share of competitive grant funding. The findings from the event study analysis suggest that this trend materialized after the enactment of the earmark moratorium. Thus there is some evidence that rather that eliminating wasteful government spending the earmark moratorium simply empowered the president in the appropriations 
process. 


\section{References:}

Albouy, D. (2013). Partisan Representation in Congress and the Geographic Distribution of Federal Funds. The Review of Economics and Statistics, 95(1), 127-141.

Alvarez, R. M., Saving, J. L. (1997). Deficits, democrats, and distributive benefits: congressional elections and the pork barrel in the 1980s. Political Research Quarterly, 50(4), 809-831.

Balla, S. J., Lawrence, E. D., Maltzman, F., Sigelman, L. (2002). Partisanship, Blame Avoidance, and the Distribution of Legislative Pork. American Journal of Political Science, 46(3), 515. https://doi.org/10.2307/3088396

Barrett, A. W., Eshbaugh-Soha, M. (2007). Presidential success on the substance of legislation. Political Research Quarterly, 60(1), 100-112.

BEA Data. (2018, August 21). Retrieved from https://www.bea.gov/data

Berry, C. R., Burden, B. C., Howell, W. G. (2010). The President and the Distribution of Federal Spending. The American Political Science Review, 104(4), 783-799. JSTOR.

Bertelli, A. M., Grose, C. R. (2009). Secretaries of Pork? A New Theory of Distributive Public Policy. The Journal of Politics, 71(3), 926-945. https://doi.org/10.1017/S002238160909080X

Bogie, J. (2018). Earmarks Won’t Fix the Broken Budget and Appropriations Process. 3353, 10. 
Cascio, E. U., Washington, E. (2014). Valuing the Vote: The Redistribution of Voting Rights and State Funds following the Voting Rights Act of $1965 *$. The Quarterly Journal of Economics, 129(1), 379-433. https://doi.org/10.1093/qje/qjt028

Clemens, A., Crespin, M., Finocchiaro, C. J. (2015a). Earmarks and Subcommittee Government in the U.S. Congress. American Politics Research, 43(6), 1074-1106. https://doi.org/10.1177/1532673X15576952

Clemens, A., Crespin, M. H., Finocchiaro, C. J. (2015b, June 15). In Congress, committees are still at the center of pork barrel politics [Online resource]. USApp- American Politics and Policy Blog.

http://blogs.lse.ac.uk/usappblog/

Collie, M. P. (1988). The Legislature and Distributive Policy Making in Formal Perspective. Legislative Studies Quarterly, 13(4), 427.

https://doi.org/10.2307/439778

Cox, G. W., McCubbins, M. D. (1986). Electoral Politics as a Redistributive Game. The Journal of Politics, 48(2), 370-389. https://doi.org/10.2307/2131098

Cox, G. W., McCubbins, M. D. (2005). Setting the Agenda: Responsible Party Government in the U.S. House of Representatives. Cambridge University Press. https://doi.org/10.1017/CBO9780511791123

De Figueiredo, J. M. D., Silverman, B. S. (2006). Academic Earmarks and the Returns to Lobbying. The Journal of Law and Economics, 29.

Dixit, A., Londregan, J. (1996). Fiscal federalism and redistributive politics. Journal of Public Economics, 68(2), 153-180. https://doi.org/10.1016/S00472727(97)00097-2

Downs, A. (1957). An Economic Theory of Political Action in a Democracy. Journal of Political Economy, 65(2), 135-150. https://doi.org/10.1086/257897 
Doyle, R. B. (2011). The Rise and (Relative) Fall of Earmarks: Congress and Reform, 2006-2010. Public Budgeting Finance, 31(1), 1-22. https://doi.org/10.1111/j.1540-5850.2011.00971.x

Eshbaugh-Soha, M. (2005). The politics of presidential agendas. Political Research Quarterly, 58(2), 257-268.

Farris, Anne, Richard Nathan, and David Wright. 2004. "The Expanding Administrative Presidency: George Bush and the Faith-Based Initiate." Rockerfeller Institute of Government, Albany NY. Report.

Ferguson, M. R. (2003). Chief executive success in the legislative arena. State Politics Policy Quarterly, 3(2), 158-182.

Fowler, A., Hall, A. B. (2015). Congressional seniority and pork: A pig fat myth? European Journal of Political Economy, 40, 42-56.

https://doi.org/10.1016/j.ejpoleco.2015.07.006 https://doi.org/10.1093/ei/cbg023

Gordon, S. (2018). What did the Earmark Ban Do? Evidence from Intergovernmental Grants. 21.

Grossman, P. J. (1994). A political theory of intergovernmental grants. Public Choice, 78(3-4), 295-303. https://doi.org/10.1007/BF01047760

Hager, G. L., Talbert, J. C. (2000). Look for the party label: Party influences on voting in the US House. Legislative Studies Quarterly, 75-99.

History, Art Archives, U.S. House of Representatives, "Presidential Vetoes," https://history.house.gov/Institution/Presidential-Vetoes/Presidential-Vetoes/ (February 12, 2020)

Hudak, J. (2014). Presidential pork : White house influence over the distribution of federal grants. Washington, D.C.: Brookings Institution Press.

Kang, W. (2018). Presidential pork barrel politics with polarized voters. Political Geography, 67, 12-22. doi:10.1016/j.polgeo.2018.09.001 
Kasdin, S., Lin, L. (2015). Strategic behavior by federal agencies in the allocation of public resources. Public Choice, 164(3-4), 309-329. https://doi.org/10.1007/s11127-015-0280-9

Kieschnick, R., McCullough, B. D. (2003). Regression analysis of variates observed on $(0,1)$ : percentages, proportions and fractions. Statistical modelling, 3(3), 193-213.

Knight, B. (2005). Estimating the Value of Proposal Power. American Economic Review, 95(5), 1639-1652. https://doi.org/10.1257/000282805775014290

Kriner, D. L., Reeves, A. (2015). Presidential particularism and divide-thedollar politics. American Political Science Review, 109(1), 155-171.

Kuhn, B. (2017). The End of the Earmark Era: The New Politicization of Federal Agency Spending. (Electronic Thesis or Dissertation). Retrieved from https://etd.ohiolink.edu/

Larcinese, V., Rizzo, L., Testa, C. (2006). Allocating the US federal budget to the states: The impact of the president. The Journal of Politics, 68(2), 447-456.

Larcinese, V., Snyder, J. M., Testa, C. (2012). Testing Models of Distributive Politics using Exit Polls to Measure Voters' Preferences and Partisanship. British Journal of Political Science, 43(4), 845-875.

https://doi.org/10.1017/S0007123412000245

Lazarus, J. (2009). Party, Electoral Vulnerability, and Earmarks in the U.S. House of Representatives. The Journal of Politics, 71(3), 1050-1061. https://doi.org/10.1017/S0022381609090872

Lazarus, J. (2010). Giving the People What They Want? The Distribution of Earmarks in the U.S. House of Representatives. 16. 
Lazarus, J., Steigerwalt, A. (2009). Different Houses: The Distribution of Earmarks in the U.S. House and Senate. Legislative Studies Quarterly, 34(3), 347-373. https://doi.org/10.3162/036298009788897772

Lee, F. E. (2003). Geographic Politics in the U.S. House of Representatives: Coalition Building and Distribution of Benefits. American Journal of Political Science, 47(4), 714-728. https://doi.org/10.1111/1540-5907.00050

Levitt, S. D., Snyder Jr, J. M. (1995). Political parties and the distribution of federal outlays. American Journal of Political Science, 958-980.

Lightman D, Wieder B. (2019). Trump states and rural areas grab bigger chunk of transportation grant funds.

https://www.msn.com/en-us/news/us/trump-states-and-rural-areas-grabbigger-chunk-of-transportation-grant-funds/ar-AADizoB

McCarty, N. (2000). Presidential pork: Executive veto power and distributive politics. The American Political Science Review, 94(1), 117-129.

Mayhew, D. R. (1974). Congress: The electoral connection (Vol. 26). Yale University Press.

Meaney, C., Moineddin, R. (2014). A Monte Carlo simulation study comparing linear regression, beta regression, variable-dispersion beta regression and fractional logit regression at recovering average difference measures in a two sample design. BMC medical research methodology, 14(1), 14.

Mills, R. W., Kalaf-Hughes, N., MacDonald, J. A. (2016). Agency policy preferences, congressional letter-marking and the allocation of distributive policy benefits*. Journal of Public Policy, 36(4), 547-571.

https://doi.org/10.1017/S0143814X15000252

MIT Election Data and Science Lab, 2017, "U.S. House 1976-2018", https://doi.org/10.7910/DVN/IG0UN2, Harvard Dataverse, V5, UNF:6:f4 KhIVuYz/VinGbLYysWJg $==[$ fileUNF $]$ 
MIT Election Data and Science Lab, 2017, "U.S. President 1976-2016", https://doi.org/10.7910/DVN/42MVDX, Harvard Dataverse, V5, UNF:6: Mw0hOUHAijKPTVRAe5jJvg== [fileUNF $]$

MIT Election Data and Science Lab, 2017, "U.S. Senate 1976-2018", https://doi.org/10.7910/DVN/PEJ5QU, Harvard Dataverse, V4, UNF: 6:WzSZLQX8O9Nk6RKWwkjx9g $==[$ fileUNF $]$

Middlemass, K. M., Grose, C. R. (2007, September). The Three Presidencies? Legislative Position Taking in Support of the President on Domestic, Foreign, and Homeland Security Policies in the 107th Congress (2001-02). In Congress the Presidency: A Journal of Capital Studies (Vol. 34, No. 2, pp. 57-80). Taylor Francis Group.

Murteira, J. M., Ramalho, J. J. (2016). Regression analysis of multivariate fractional data. Econometric Reviews, 35(4), 515-552.

Papke, L. E., Wooldridge, J. M. (1996). Econometric methods for fractional response variables with an application to $401(\mathrm{k})$ plan participation rates. Journal of applied econometrics, 11(6), 619-632.

Papke, L. E., Wooldridge, J. M. (2008). Panel data methods for fractional response variables with an application to test pass rates. Journal of econometrics, 145(1-2), 121-133.

Scheck, T., Busche, K. (2019). How Congress, Trump and Obama played favorites with transportation money - APM Reports.

https://www.apmreports.org/story/2019/05/23/congress-earmarks-tiger-buildgrants

Sciara, G.-C. (2012). Peering Inside the Pork Barrel: A Study of Congressional Earmarking in Transportation. Public Works Management Policy, 17(3), 217-237. https://doi.org/10.1177/1087724X12445777 
Shepsle, K. A., Weingast, B. R. (1981). Political Preferences for the Pork Barrel: A Generalization. American Journal of Political Science, 25(1), 96. https://doi.org/10.2307/2110914

Stein, R. M., Bickers, K. N. (1994a). Congressional Elections and the Pork Barrel. 23.

Stein, R. (1981). The Allocation of Federal Aid Monies: The Synthesis of Demand-Side and Supply-Side Explanations. American Political Science Review, 75(2), 334-343. doi:10.2307/1961368

Stewart, C. (2017, November 17). Charles Stewart's Congressional Data Page. Retrieved from http://web.mit.edu/17.251/www/data_page.html

Stromberg, D. (2004). Radio's Impact on Public Spending. The Quarterly Journal of Economics, 119(1), 189-221.

https://doi.org/10.1162/003355304772839560

Ting, M. M. (2012). Legislatures, Bureaucracies, and Distributive Spending. American Political Science Review, 106(2), 367-385.

https://doi.org/10.1017/S0003055412000081

U.S. Census Bureau. (2020, March 12). TIGER/Line Shapefiles. Retrieved from https://www.census.gov/geographies/mapping-files/time-series/geo/tigerline-file.html

U.S. Census Bureau. (2019, December 3). Population Estimates Categorical Variables. Retrieved from https://www.census.gov/data/developers/datasets/popest-popproj/popest/popest-vars.Vintage_2017.html

Weingast, B. R. (1979). A Rational Choice Perspective on Congressional Norms. American Journal of Political Science, 23(2), 245.

https://doi.org/10.2307/2111001 https://doi.org/10.2307/449012 
Weingast, B. R., Shepsle, K. A., Johnsen, C. (1981). The Political Economy of Benefits and Costs: A Neoclassical Approach to Distributive Politics. Journal of Political Economy, 89(4), 642-664. https://doi.org/10.1086/260997 White, J. (2015). Jimmy Carter's and James Miller's Revenge: The Reasons and the Consequences for Presidential and Congressional Power of Measures to Ban Congressional "Earmarks." Case Western Reserve Law Review, 65(4), $1175-1199$.

Yildirim, H. (2007). Proposal power and majority rule in multilateral bargaining with costly recognition. Journal of Economic Theory, 136(1), 167-196. https://doi.org/10.1016/j.jet.2006.07.008

Young, A. T., Sobel, R. S. (2013). Recovery and Reinvestment Act spending at the state level: Keynesian stimulus or distributive politics? Public Choice, 155(3-4), 449-468. https://doi.org/10.1007/s11127-011-9876-x 
Appendices 
Two central challenges to the aggregation process existed. First, if some grant funds were given back to the federal government or reallocated, the total grant variable was entered as a negative variable. Funds were often awarded in year $t$ and then the excess returned in year $t+1$. This creates a problem when summing by state (congressional district); and year. There are three possibilities. First, the amount of funds awarded in year $t+1$ is greater than the excess funds from year $t$. Thus the total grant funding variable is positive. Second, the amount of funds awarded in year $t+1$ is equal to the excess funds from year $t$. The means that the total grant funding variable will have a value of zero. Third, the amount of funds in year $t+1$ is less than the excess funds from year $t$. Therefore, the total grant funding variable would have a negative value because the state (congressional district) returned more funds to the federal government than the received from the federal government in year $t+1$. For the small portion of aggregate observations with negative total grant funds the value was changed to zero.

The second issue in the aggregation process was missing observations for congressional districts. Missing observations for congressional districts took two forms. First, no congressional district entered in the data. Second, the recorded congressional district did not exist. The latter was assumed to be a miss-entered district. In both cases efforts were made to recover as many of the true congressional districts as possible.

Calculating the total grant funding variable for the H.O.R. data set was more complicated due to the presence of missing and mis-entered districts. This variable was calculated by summing the dollar amount of every grant awarded to a congressional district in a given year. However, a number of data pre-processing steps were necessary to ensure that the congressional district was correctly specified. First, a master list of congressional district for each year in the sample was create from the U.S. Census TIGER shape files (U.S. Census Bureau, 2020). Then every district was checked against the master list to determine whether that district did in fact exist. If the district had a match in the master list then no 
more pre-processing was necessary. However, if the district did not have a match then the state in which the congressional district was located in was compared with was compared with a list of at large state in each given year. If there was a match then the district was re-coded as zero, otherwise it continued to remain unknown.

Next a geospatial database of all US states, congressional districts, and counties was created in arcGIS using TIGER share files (U.S. Census Bureau, 2020). The congressional district were then spatially joined to their respective counties (counties with more than one congressional district where excluded from the join). Once this was complete the data was exported from arcGIS. All of the counties associated with the unknown congressional were match with counties from the GIS data. Districts with matches were re-coded to the correct district; the remaining districts continued to the final pre-processing stage. In the final stage another geospatial database was created that contained data on US states, congressional districts, and ZIP codes. ZIP codes were spatially joined to the corresponding congressional district (ZIP code in more than one district were dropped). The ZIP codes of remaining missing district were compared with newly created list. If there was a match the district was re-coded to the correct value, otherwise it was dropped from the analysis.

Unfortunately even after all of the pre-processing a significant portion of the congressional districts remained unknown, and therefore, must be excluded from the analysis. This amounts to 477,913 observations, or approximately $13.55 \%$ of grants in the sample. The dollar value of these missing districts ranges from $-752,877,282 \$$ to $1,921,000,000 \$$, with a mean of $430874.80 \$$ and a median of 142984\$. There are also 3,709 observation that take on a value of zero, and 31,949 observations that take on negative values. There are unknown Congressional districts for 43 of the 50 states. These state include the following: Alabama, Arizona, Arkansas, California, Colorado, Connecticut, Florida, Georgia, Hawaii, Idaho, Illinois, Indiana, Iowa, Kansas, Kentucky, Louisiana, Maine, Maryland, 
Massachusetts, Michigan, Minnesota, Mississippi, Missouri, Nebraska, Nevada, New Hampshire, New Jersey, New Mexico, New York, North Carolina, Ohio, Oklahoma, Oregon, Pennsylvania, Rhode Island, South Carolina, Tennessee, Texas, Utah, Virginia, Washington, West Virginia, and Wisconsin. 